\title{
Induction of p19INK4d in response to ultraviolet light improves DNA repair and confers resistance to apoptosis in neuroblastoma cells
}

\author{
Julieta M Ceruti ${ }^{1}$, María E Scassa ${ }^{1}$, Juan M Fló2, Cecilia L Varone ${ }^{1}$ and Eduardo T Cánepa*,1 \\ ${ }^{1}$ Laboratorio de Biología Molecular, Departamento de Química Biológica, Facultad de Ciencias Exactas y Naturales, Universidad de \\ Buenos Aires, Ciudad Universitaria Pabellón II Piso 4, 1428 Buenos Aires, Argentina; ${ }^{2}$ Laboratorio de Inmunoquímica, Departamento \\ de Química Biológica, Facultad de Ciencias Exactas y Naturales, Universidad de Buenos Aires, Ciudad Universitaria Pabellón II Piso \\ 4, 1428 Buenos Aires, Argentina
}

\begin{abstract}
The genetic instability driving tumorigenesis is fuelled by DNA damage and by errors made by the DNA replication. Upon DNA damage the cell organizes an integrated response not only by the classical DNA repair mechanisms but also involving mechanisms of replication, transcription, chromatin structure dynamics, cell cycle progression, and apoptosis. In the present study, we investigated the role of p19INK4d in the response driven by neuroblastoma cells against DNA injury caused by UV irradiation. We show that p19INK4d is the only INK4 protein whose expression is induced by UV light in neuroblastoma cells. Furthermore, p19INK4d translocation from cytoplasm to nucleus is observed after UV irradiation. Ectopic expression of p19INK4d clearly reduces the UV-induced apoptosis as well as enhances the cellular ability to repair the damaged DNA. It is clearly shown that DNA repair is the main target of p19INK4d effect and that diminished apoptosis is a downstream event. Importantly, experiments performed with CDK4 mutants suggest that these p19INK4d effects would be independent of its role as a cell cycle checkpoint gene. The results presented herein uncover a new role of p19INK4d as regulator of DNAdamage-induced apoptosis and suggest that it protects cells from undergoing apoptosis by allowing a more efficient DNA repair. We propose that, in addition to its role as cell cycle inhibitor, p19INK4d is involved in maintenance of DNA integrity and, therefore, would contribute to cancer prevention.

Oncogene (2005) 24, 4065-4080. doi:10.1038/sj.onc. 1208570 Published online 7 March 2005
\end{abstract}

Keywords: apoptosis; CDK4/6; DNA repair; INK4; neuroblastoma; UV

\section{Introduction}

Cell proliferation is positively regulated by cyclindependent kinases (CDKs). In neural as in other somatic

\footnotetext{
*Correspondence: ET Cánepa; E-mail: ecanepa@qb.fcen.uba.ar Received 11 November 2004; revised 10 January 2005; accepted 24 January 2005; published online 7 March 2005
}

cells, progression through the G1 phase of the cell cycle depends upon the activities of cyclin D-dependent CDK4 or CDK6 and, later, on cyclin E-dependent CDK2 (Murray, 2004; Sherr, 2004). These enzymes cooperate to phosphorylate the retinoblastoma protein, inhibiting its growth-suppressive function and initiating an E2F-dependent transcriptional program that is necessary for entry into the $\mathrm{S}$ phase of the cell cycle (Dyson, 1998; Malumbres and Barbacid, 2001; Trimarchi and Lees, 2002). Cyclin-CDK complexes are negatively regulated by small polypeptides, the CDK inhibitors (CKIs) that, in mammalian cells, fall into one of two distinct families (Sherr and Roberts, 1999). The INK4 family includes four members, p16INK4a, p15INK4b, p18INK4c, and p19INK4d, that specifically bind to and inhibit CDK4/CDK6 (Roussel, 1999; Ortega et al., 2002). The Cip/Kip family consists of three proteins, p21Cip1, p27Kip1, and p57Kip2. Whereas Cip/Kip family members act as negative regulators of cyclin $\mathrm{E}-$ and $\mathrm{A}-\mathrm{CDK} 2$ and cyclin BCDK1 holoenzymes (Hengst and Reed, 1998; Nakayama, 1998), they also act as positive regulators of cyclin D-CDK4/6 complexes by mediating their assembly early in G1 (Cheng et al., 1999).

The four proteins of the INK4 family share a similar structure dominated by several ankyrin repeats, and the corresponding genes contain an intron which interrupts the coding sequence at the same position, indicating that they have evolved from a common ancestor (Ruas and Peters, 1998). Although they appear to be structurally redundant and equally potent as inhibitors, the INK4 family members are differentially expressed during mouse development (Cunningham and Roussel, 2001). Moreover, in terms of biological functions, different inhibitors appear to participate in regulation and coordination of cell cycle events following mitogenic stimulation, mitogen deprivation, or changes in cell-cell or cell-matrix interactions (Harper and Elledge, 1996), and they have also been implicated in inducing terminal differentiation and cellular aging or senescence (Zindy et al., 1997b, 1999). Apart from their physiological roles, the INK4 proteins are commonly lost or inactivated by mutations in diverse types of cancer, and they represent established or candidate tumor suppressors. Thus, inactivation of p16 through gene deletions, point 
mutations, or transcriptional silencing by promoter methylation is among the most frequent defect contributing to oncogenesis (Sharpless et al., 2001, 2004) and, although much less extensive, there are also evidences for abnormalities of the other INK4 proteins in some tumors (Chaussade et al., 2001; Bai et al., 2003). In addition, the striking diversity in the pattern of expression of INK4 genes suggested that this familiy of cell cycle inhibitors might have cell lineage-specific or tissue-specific functions (Roussel, 1999). Given their emerging roles in fundamental physiological as well as pathological processes, an important question has raised about the diverse roles for the individual INK4 family members in cell cycle control, cellular differentiation, and multistep oncogenesis.

The notion that cancer is caused by mutations in genes critical for the control of cell growth implies that genome stability is important for preventing oncogenesis. A great diversity of lesions arises in DNA from environmental agents such as the ultraviolet component of sunlight, ionizing radiation, and numerous genotoxic chemicals, which, if left unrepaired, may lead to mutations that enhance cancer risk (Hoeijmakers, 2001). Exposure to UV radiation induces a variety of cellular responses comprising transcriptional induction of a number of genes, including $c$-jun, $c$-fos, and TP53 (Rittie and Fisher, 2002; Sun et al., 2004) and cell cycle effects (Milligan et al., 1998; Lutzen et al., 2004). However, little is known regarding the mechanisms by which UV light affects the cell cycle machinery.

Following DNA damage normal cells arrest their proliferation at cell cycle checkpoints, the most prominent of which occur at the G1/S and G2/M boundaries. Arrest allows time for repair prior to continued cell cycle progression. During tumor progression, loss of the G1 arrest checkpoint in response to DNA damage is essential for the eventual emergence of a malignant clone. One G1 arrest checkpoint is controlled by p53 (Minella et al., 2002; Sancar et al., 2004). In response to DNA damage, p53 level increases by a posttrancriptional mechanism, resulting in the transcriptional activation of p21Cip which can mediate G1 arrest (Nayak and Das, 2002). This may explain why most tumors with wild-type (wt) retinoblastoma are linked with loss of p53 function due to inactivation of the $p 53$ gene or as a result of epigenetic effects (Wang et al., 2004). However, some malignant cells do express wt p53. We hypothesize that these cells may not have a fully competent G1 arrest checkpoint in response to DNA damage, despite the presence of $\mathrm{p} 53$. In this context, it is reasonable to presume that other molecules, like INK4 proteins, which inhibit CDK4/6 activities causing a G1-phase arrest, may be necessary to reinforce this response.

In most cancers, defective apoptosis is related to the uncoordinated cellular growth, allowing neoplastic cells to survive beyond their normal lifespan and elude multiple cellular controls (Hahn and Weinberg, 2002). Consequently, cellular resistance to apoptotic signals constitutes a major step in carcinogenesis. Furthermore, defective apoptosis affects the therapeutic result, given that the majority of agents used in cancer treatment activate apoptotic pathways to precipitate cell death (Johnstone et al., 2002). While DNA damage caused by UV light is known to be responsible for UV-induced genotoxicity, its role in triggering apoptosis is still unclear.

In the present study, we investigated the role of p19INK4d in the response driven by neuroblastoma cells against DNA injury caused by UV irradiation. The highest level of p19INK4d protein expression occurs in brain, testis, spleen, and thymus. p19INK $4 d$ is relatively well characterized in the central nervous system, where is one of the major INK4 proteins. It is expressed early during brain development and its expression is maintained into adulthood (Zindy et al., 1997b). In contrast with the other INK4, only p19INK4d expression is periodic through the cell cycle (Thullberg et al., 2000; Ortega et al., 2002). In this report, we show that p19INK4d (hereafter referred as p19) is the only INK4 protein whose expression is induced by UV light in neuroblastoma cells. Furthermore, p19 translocation from cytoplasm to nucleus is observed after UV irradiation. Importantly, ectopic expression of p19 clearly reduces the UV-induced apoptosis, as well as enhances the cellular ability to repair damaged DNA. Experiments performed with a CDK4 mutant suggest that these p19 effects would be independent of its role as cell cycle checkpoint gene. The results presented herein uncover a new role of p19 as regulator of DNA-damageinduced apoptosis and suggest that p19 protects cells from undergoing apoptosis by allowing a more efficient DNA repair.

\section{Results}

Periodic expression of p19INK4d during neuroblastoma cell cycle

Neuroblastoma is one of the most common malignancies in childhood. It derives from the neural crest which gives rise to multiple cell lineages with neuronal or melanocytic phenotypes (Sadee et al., 1987). Unlike other tumor types, nearly all human neuroblastomas were found to carry wt p53 gene (Hosoi et al., 1994). These cell lines are therefore suitable model systems for investigating regulation and functions of proteins in a wt p53 context.

Due to the lack of studies relevant to p19 protein in neuroblastoma cells, we first analysed the expression of p19 and its regulation throughout the cell cycle. Neuroblastoma cells were arrested in early G1 by serum starvation during $36 \mathrm{~h}$ and then induced to re-enter the cell cycle synchronously by readdition of fetal serum. Figure 1a shows that p19 mRNA could not be detected in starved, quiescent cells (time $0 \mathrm{~h}$ ) as well in cells entering G1 phase. However, as cells approached the mid-G1 and G1/S transition, p19 mRNA synthesis was abruptly reinitiated and increased as the cell progressed through the $\mathrm{S}$ phase to fall again through the remainder of the cycle. Maximal average of dividing cells was 

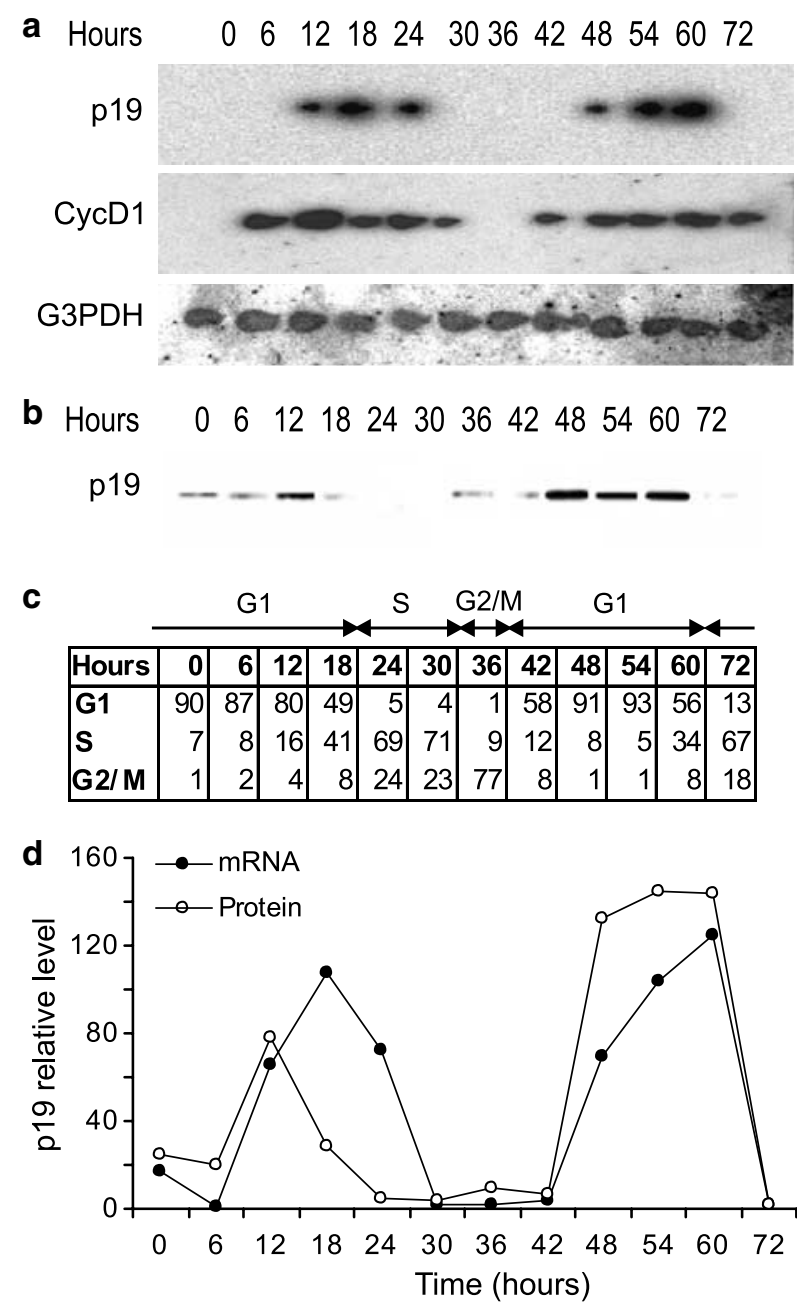

Figure 1 Expression of p19 during the neuroblastoma cell cycle. SH-SY 5Y cells were arrested in early G1 phase by serum starvation for $36 \mathrm{~h}$, and then restimulated with serum to enter the cell cycle synchronously. (a) Total RNA $(20 \mu \mathrm{g})$ extracted from cells at the indicated times were subjected to Northern blot analysis with the ${ }^{32} \mathrm{P}$-labeled probes indicated at the left margin. (b) Equal amounts of proteins from cell lysates prepared at the indicated times were immunoprecipitated using a polyclonal anti-p19 antibody. The immune complexes were subjected to $10 \%$ SDS-PAGE, transferred to nitrocellulose membrane, and analysed by Western blot with the same anti-p19 antibody. (c) The cell cycle phases were determined by flow-cytometric analysis of cellular DNA content. (d) Levels of p19 mRNA and p19 protein, as quantitated with a Bio-Imaging Analyzer. CycD1, cyclin D1; G3PDH, glyceraldehyde-3-phosphate dehydrogenase

observed at 34-38 h (Figure 1c). Although the cells appear to lose synchrony in the second cycle, p19 mRNA levels were again increased at the end of G1 and $\mathrm{S}$ phase $(48 \mathrm{~h})$. The relative abundance of p19 mRNA, determined by Northern blot scanning, is summarized graphically at the bottom of the figure (Figure 1d). The kinetics of induction of p19 mRNA is readily distinguishable from that of cyclin D1 mRNA, which is induced early in G1 phase and oscillates as cells continue to proliferate. The expression of the housekeeping gene, glyceraldehyde-3 phosphate dehydrogenase, showed minimal oscillations throughout the cycle (Figure 1a).
Consistent with the kinetics of p19 mRNA expression in synchronized neuroblastoma cells, synthesis of p19 protein was increased near the G1/S boundary, decreased as cell divided and re-entered a second G1 phase, and augmented again during the late G1 and the following S phase (Figure 1b). Therefore, p19 mRNA and protein synthesis in neuroblastoma cells are periodic with relative induction between late $\mathrm{G} 1$ and $\mathrm{S}$ phases.

\section{p19 is the only INK4 gene induced by UV irradiation in neuroblastoma cells}

To test our hypothesis that INK4 proteins are an important element in the cellular response evoked by UV-damaged DNA, we first analysed whether p19INK4d would respond to UV in the human neuroblastoma cell line SH-SY5Y. We found that there was a clear and transient induction of p19 at $24 \mathrm{~h}$ after UV irradiation and that this induction was dependent on the UV doses (Figure 2a and 2c). To assess the possibility that the induction was attributable to transcriptional regulation, we examined the mRNA level at various postirradiation time points. We observed that p19 mRNA was significantly induced at $24 \mathrm{~h}$ after $8 \mathrm{~mJ} / \mathrm{cm}^{2}$ UV treatment (Figure 2d). These results suggest that UV induced the expression of p19INK4d mainly at pretranslational step. As expected, p53 levels were increased after UV irradiation, whereas CDK4 protein remained unaffected (Figure $2 b$ ).

When SH-SY5Y cells were irradiated with $8 \mathrm{~mJ} / \mathrm{cm}^{2}$ $\mathrm{UV}$, nearly $65 \%$ cells arrested at G1 after $48 \mathrm{~h}$ in contrast with $50 \%$ of nonirradiated cells that presented a G1 DNA content as measured by FACS analysis. The response to DNA-damaging agent was a true cell cycle arrest since the proportion of cells in S phase decreased from $33 \%$ in untreated cells to $9 \%$ after UV treatment. In addition, $48 \mathrm{~h}$ after irradiation, the cell number, the metabolic activity, and the thymidine incorporation were significantly reduced as compared with nonirradiated neuroblastoma cells (data not shown). Cell cycle analysis indicated an increase in the number of dead cells $48 \mathrm{~h}$ after exposure to UV radiation (sub-G1 population, $13.6 \%$ ) in comparison to untreated cells (sub-G1 population, 3.5\%) (Figure 2d). To assess whether the UV-mediated induction of $\mathrm{p} 19$ is a common event rather than a cell type-specific observation, we investigated p19 expression in response to UV irradiation in different cell lines. Interestingly, other human or murine neuroblastoma cells, like IMR-32 or Neu-2a, HepG2 cells derived from human hepatoma, BHK cells from hamster kidney and mouse tumoral Leydig cells, MA-10, showed increased p19 mRNA level after being challenged with a UV fluence of $8 \mathrm{~mJ} / \mathrm{cm}^{2}$ (data not shown).

We then turned our attention to the effect of UV on the expression of the other INK4 inhibitors. Neuroblastoma cells were treated with $8 \mathrm{~mJ} / \mathrm{cm}^{2}$ UV light and RNA samples from cell lysates were isolated at different times after genotoxic exposure. Expression of various CKIs was analysed by Northern blotting. As expected, p21 expression was strikingly increased in irradiated 
cells. However, the mRNA levels of p16, p15, and p18 remained unchanged up to $96 \mathrm{~h}$ from the time of UV treatment (Figure 3).

\section{UV irradiation leads to subcellular redistribution of p19INK4d}

Previous work has reported a predominantly cytoplasmic localization of p19 in several cellular types (Guan et al., 1996). The subcellular distribution of endogenous p19 in cycling neuroblastoma cells was determined in fixed cells by immunocytochemistry using an anti-p19

a

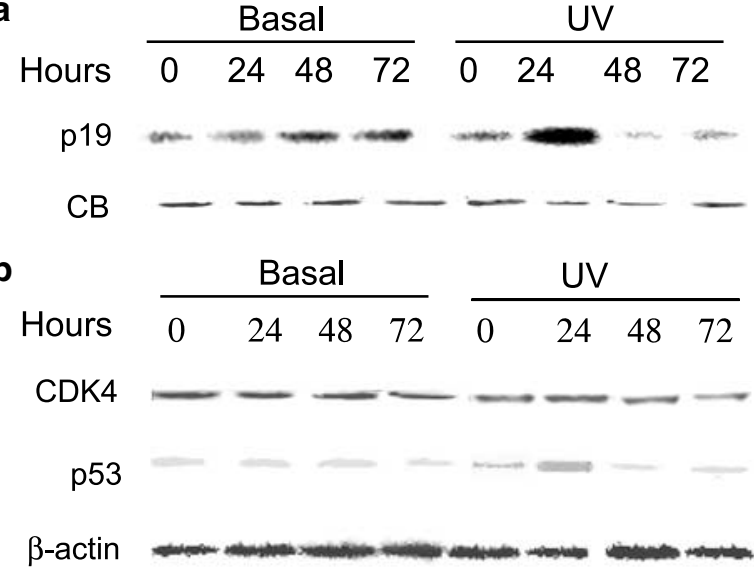

C

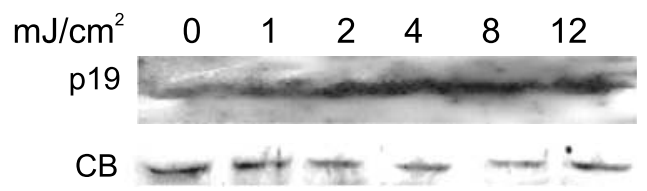

d
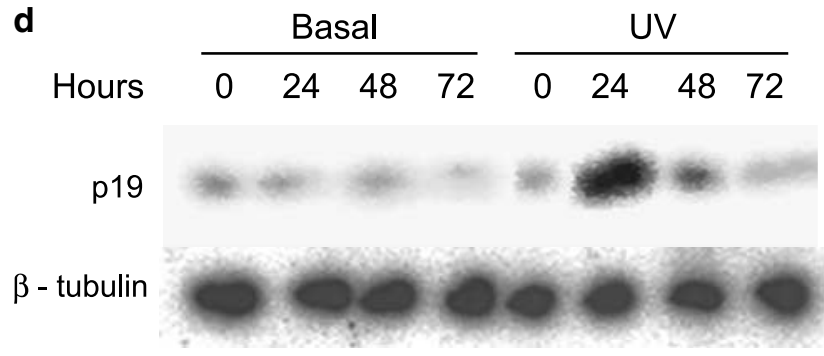

e

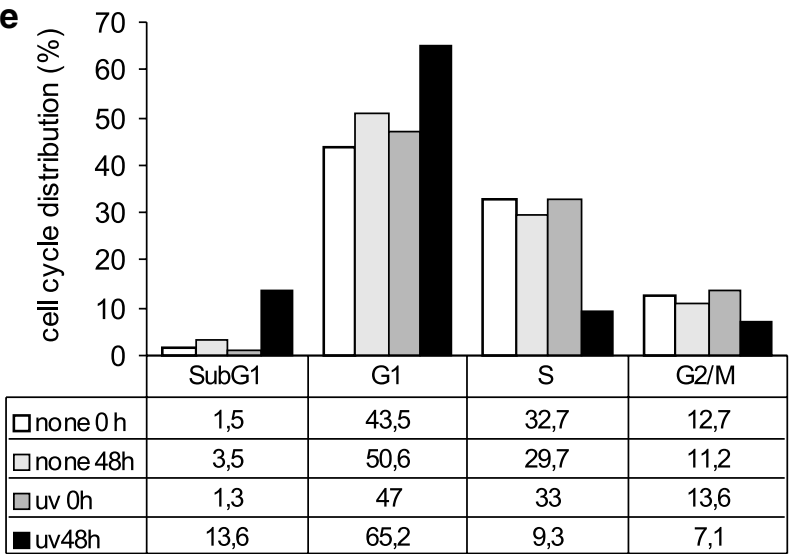

antibody and FITC-conjugated secondary antibody. Protein p19 was detected by fluorescence microscopy in only $43 \%$ of the analysed cells, that is consistent with the periodic expression of this protein through the cell cycle. In line with previous observation, p19 was almost exclusively cytoplasmic ( $93 \%$ of the p19-positive cells) (Figure 4 and Table 1).

We next asked whether p19 subcellular localization could be modified after UV irradiation. SH-SY5Y were irradiated with $8 \mathrm{~mJ} / \mathrm{cm}^{2} \mathrm{UV}$, fixed at different times, and p19 was visualized by indirect immunofluorescence. As illustrated in Figure 4 and quantified in Table 1, $24 \mathrm{~h}$

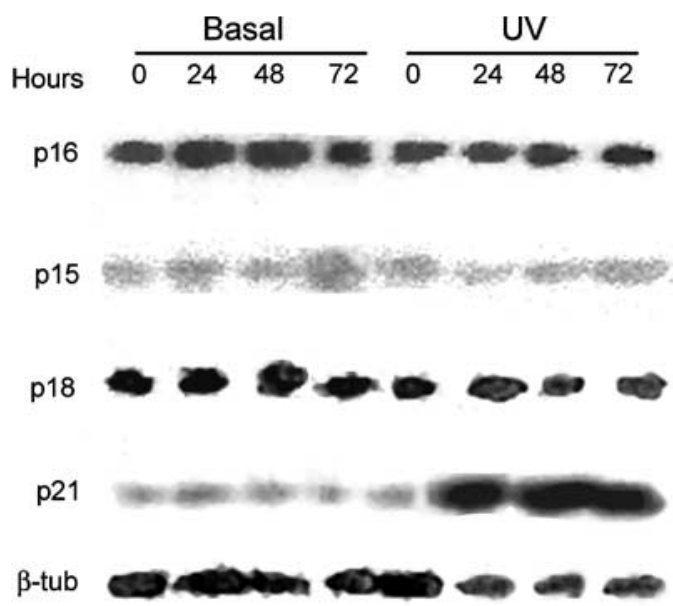

Figure 3 Analysis of INK4 and Cip/Kip mRNA after UV irradiation. SH-SY5Y cells were irradiated with $8 \mathrm{~mJ} / \mathrm{cm}^{2}$ UV and harvested at the indicated times following irradiation. Total RNA $(20 \mu \mathrm{g})$ was extracted from cells and subjected to Northern blot analysis using the ${ }^{32} \mathrm{P}$-labeled probes indicated in the left margin. Each figure shows a representative autoradiograph of two independent experiments with similar results. $\beta$-tub, $\beta$-tubulin

Figure 2 Enhancement of p19 expression after UV irradiation. SH-SY5Y cells were irradiated with $8 \mathrm{~mJ} / \mathrm{cm}^{2} \mathrm{UVC}$ and harvested at the indicated times following irradiation $(\mathbf{a}, \mathbf{b})$, or irradiated with the indicated UV doses and cell lysates prepared $24 \mathrm{~h}$ after irradiation $(\mathbf{c})$. (a, c). Equal amounts of proteins from cell lysates $(100 \mu \mathrm{g})$ were immunoprecipitated using a polyclonal anti-p19 antibody. The immune complexes were subjected to $10 \%$ SDSPAGE, transferred to nitrocellulose membrane, and analysed by Western blot with the same anti-p19 antibody. Prior to immunoprecipitation, cell lysates were subjected to SDS-PAGE and Coomasie Blue staining to ensure equal protein content. The photograph shows a representative band. (b) Western blot analysis of p53 and CDK4 were carried out with $20 \mu \mathrm{g}$ of total cellular proteins extracted from SH-SY5Y cells and detected with p53 and CDK4 polyclonal antibodies. Anti- $\beta$-actin antibody was used as a protein loading control. (d) SH-SY5Y cells were irradiated with $8 \mathrm{~mJ} / \mathrm{cm}^{2}$ UVC and harvested at the indicated times following irradiation. Total RNA $(20 \mu \mathrm{g})$ was extracted from cells and subjected to Northern blot analysis using a ${ }^{32} \mathrm{P}$-labeled probe specific for human p19 mRNA and reprobed for $\beta$-tubulin mRNA. (e) At $48 \mathrm{~h}$ after UV irradiation, cells were harvested and subjected to flow cytometric cell cycle analysis. In (a)-(e) each figure shows a representative autoradiograph of three independent experiments with similar results. $\mathrm{CB}$, Coomasie Blue 

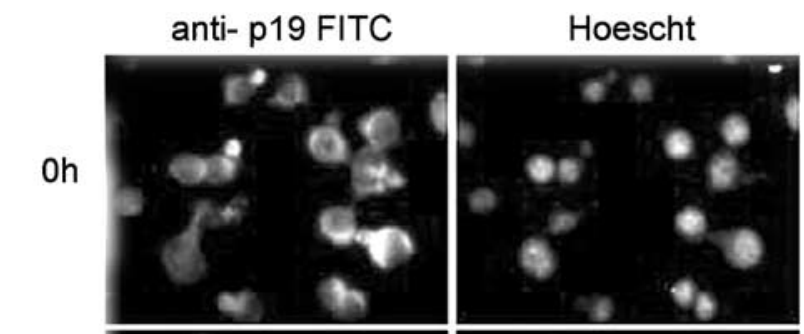

$24 \mathrm{~h}$
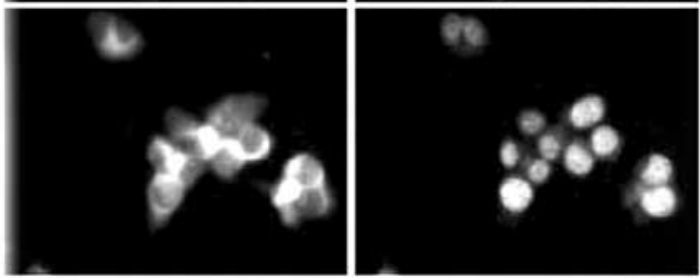

$36 \mathrm{~h}$
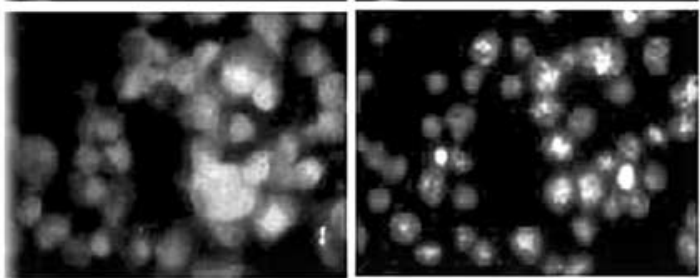

$48 \mathrm{~h}$
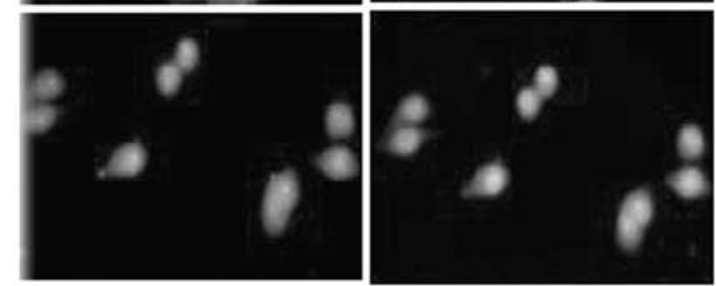

$72 \mathrm{~h}$
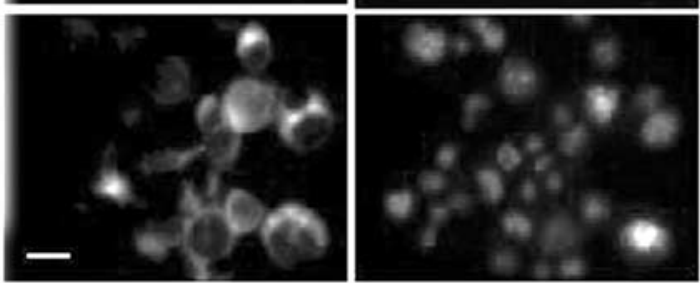

Figure 4 Subcellular localization of p19 following UV irradiation SH-SY5Y cells were treated with $8 \mathrm{~mJ} / \mathrm{cm}^{2} \mathrm{UV}$ light. At different time points after irradiation, cells were fixed and immunostained using polyclonal anti-p19 antibody and anti-IgG secondary antibody conjugated to fluorescein isothiocyanate. Nuclei were visualized using Hoescht 33248 staining. Representative results are shown. Scale bar $=10 \mu \mathrm{m}$

following UV irradiation the number of cells, in which p19 was detected, was increased by about $60 \%$ although they displayed the same subcellular distribution. After further $12 \mathrm{~h}$ ( $36 \mathrm{~h}$ time point), p19 became translocated to the nucleus with a maximum reached at $48 \mathrm{~h}$, when an eightfold increase in the number of cells exhibiting nuclear p19 was observed when compared with the control ones. In addition, at this time $75 \%$ of neuroblastoma cells were positive for p19. After $72 \mathrm{~h}$ irradiation, the number of cells expressing p19 was diminished. At this time point, p19 exhibited a subcellular distribution that resembled the one of the unirradiated state.
p19INK4d improves DNA repair in response to UV-damage JM Ceruti et al

Table 1 Subcellular localization of p19 in SH-SY5Y cells treated with UV light

\begin{tabular}{lllll}
\hline & \multicolumn{4}{c}{$\%$ of cells $^{a}$} \\
\cline { 2 - 4 } Time after $U V(h)$ & p19 positive & \multicolumn{2}{c}{ p19 positive } & \multirow{2}{*}{ p19 negative } \\
\cline { 2 - 4 } & Total & Cytoplasmic & Nuclear \\
\hline 0 & $43(136)$ & $93(126)$ & $7(10)$ & $57(182)$ \\
24 & $68(54)$ & $89(48)$ & $11(6)$ & $32(26)$ \\
36 & $60(195)$ & $66(128)$ & $34(67)$ & $40(132)$ \\
48 & $75(138)$ & $42(58)$ & $54(80)$ & $25(45)$ \\
72 & $55(50)$ & $90(45)$ & $10(5)$ & $45(40)$ \\
\hline
\end{tabular}

Data are from a single experiment, representative of two independent experiments. ${ }^{a}$ Data in parenthesis refer to number of cells

\section{p19INK4d overexpression protects neuroblastoma cells from death evoked by UV irradiation}

DNA damage may, by some means, activate components of the cellular machinery in neurons that would participate in activation of apoptotic pathways. Previous studies suggested that neuronal death caused by DNA-damaging agents requires the participation of CDKs involved in G1 to S progression (Park et al., 1998). To assess the role of p19, a CKI, in cell death after UV irradiation, we performed flow-cytometric analysis to determine the percentage of UV-dependent cell death in SH-SY5Y cells expressing high or low p19 levels. To do this, expression vectors encoding sense or antisense p19 cDNA were transfected into SH-SY5Y cells along with a puroBABE vector, which conveys resistance to puromycin. Figure 5a shows the effectiveness of the expression plasmids in puromycin-selected cells. The level of p19INK4d expressed in these cells was strongly enhanced when the sense vector was transfected. On the other hand, we were unable to detect p19 in cells that ectopically express the antisense version, even after UV irradiation.

The puromycin-selected cells were sham-treated or challenged with a UV fluence of $8 \mathrm{~mJ} / \mathrm{cm}^{2}$. Irradiated and nonirradiated cells were incubated for different periods of time (0-96h). We examined whether enhancing or impairing p19 expression might affect the extent of cell death following UV irradiation. The sub-G1 population, that corresponds to dead cells, represents only a minor fraction of the nonirradiated SH-SY5Y cells ( $2 \%$ after $48 \mathrm{~h}$ of incubation); however, when these cells were UV-irradiated, the proportion of sub-G1 population reached $18.4 \%$ (Figure 5b). Importantly, SH-SY5Y cells displaying high level of p19 exhibited resistance to UV irradiation. At $48 \mathrm{~h}$ following $\mathrm{UV}$ treatment, only $9.7 \%$ of these cells underwent cellular death. This indicates that the proportion of UV-induced sub-G1 population is two times lower in p19 overexpressing than in nontransfected SH-SY5Y cells. Conversely, flow cytometry analysis $48 \mathrm{~h}$ following UV irradiation showed that cell death was significantly increased in neuroblastoma cells with undetectable level of p19 (sub-G1 population, 33.6\%) (Figure 5b). 
a

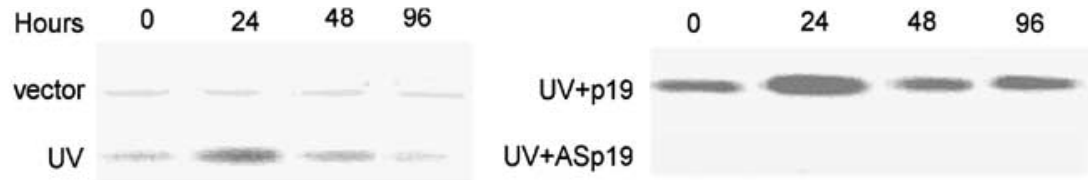

b none

UV
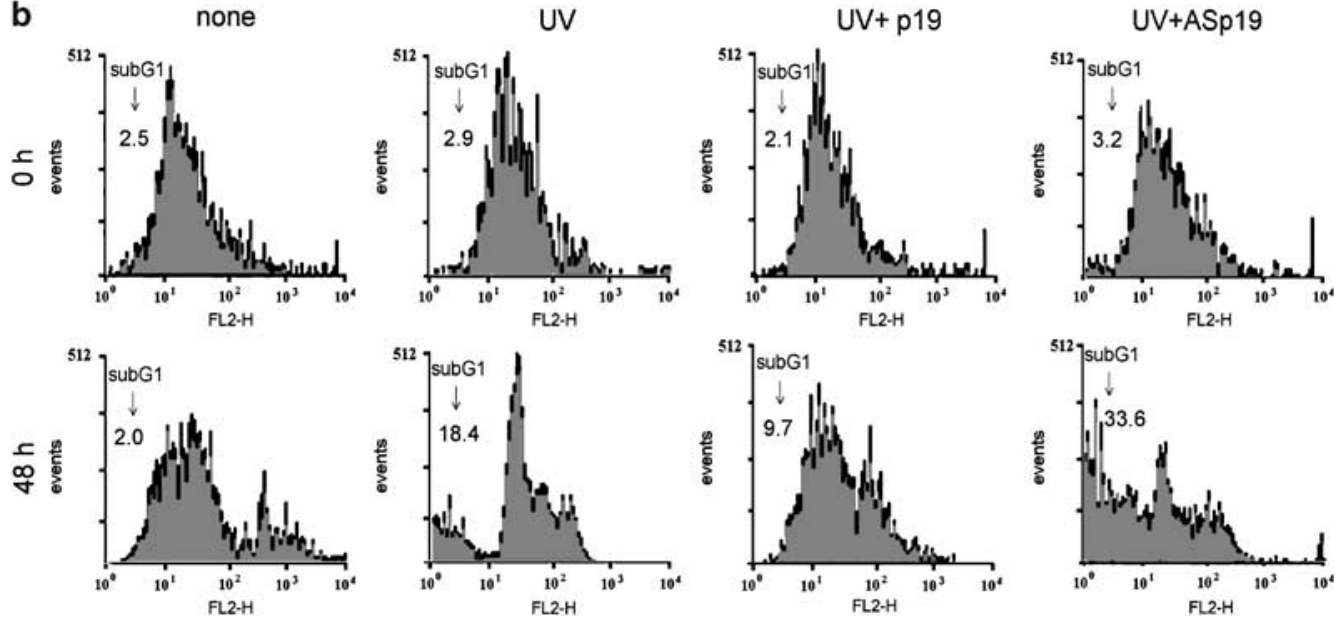

Figure 5 p19 overexpression diminishes subG1 population of UV-irradiated neuroblastoma cells. SH-SY5Y cells were transfected with $2 \mu \mathrm{g}$ of the expression vector encoding sense (p19) or antisense p19 (ASp19) cDNA or the empty vector along with $0.5 \mu \mathrm{g}$ of puroBABE. At $24 \mathrm{~h}$ after transfection, cells were treated for an additional $60 \mathrm{~h}$ with puromycin. Resistant cells were irradiated with $8 \mathrm{~mJ} / \mathrm{cm}^{2}$ UV light. (a) At the indicated times after irradiation, cells were harvested and cell lysates were prepared from each culture. Equal amounts of proteins from cell lysates were immunoprecipitated using a polyclonal anti-p19 antibody. The immune complexes were subjected to $10 \%$ SDS-PAGE, transferred to a nitrocellulose membrane, and analysed by Western blot with the same anti-p19 antibody. (b) Immediately and $48 \mathrm{~h}$ after UV irradiation, cells were harvested and subjected to flow-cytometric cell cycle analysis. Percentage of subG1 population is indicated in each graph

To confirm the quantification of dead cells obtained by flow cytometry and the apoptotic characteristics of dying cells, we determined caspase-3 activity and the internucleosomal fragmentation of DNA in cells exposed to UV and transfected with p19 sense or antisense encoding vector. The activation of caspases plays a pivotal role in the execution phases of apoptosis. Activated effector caspases, like caspase-3, accomplish the final cell death program through the degradation of vital proteins. The induction of caspase-3 activity revealed that neuroblastoma cells underwent apoptosis after UV exposure (Figure 6). The extent of induction of caspase-3 activity was increased in cells transfected with antisense p19. Conversely, a significant reduction of caspase-3 activity was observed in cells overexpressing p19. Another typical molecular characteristic of apoptosis is genomic DNA cleavage into internucleosomal segments attributed to the specific activation of an endogenous endonuclease. This apoptosis-specific parameter was assessed by DNA fragmentation assay. In support of the above results, DNA fragmentation following genotoxic insult was induced in UV-irradiated cells. This UV internucleosomal fragmentation was still higher in cells transfected with p19 antisense vector and diminished in p19-overexpressing cells (data not shown).

As a whole, these results indicate that after UV exposure neuroblastoma cells undergo apoptosis, and strongly suggest an implication of p19 in the protection from apoptotic death triggered by DNA damage.

\section{Overexpression of p19 increases the repair of $U V$-damaged DNA}

A major cellular defense mechanism by which cells respond to cytotoxic effect of UV is via activation of DNA repair pathways (Guan et al., 1996). Therefore, it is possible that p19 is protecting cells from undergoing apoptosis in response to UV damage, by allowing more efficient repair of DNA photolesions. We assessed this possibility by examining the overall repair capacity of cells subjected to conditions which may modulate the cytotoxic effects caused by UV light. To investigate whether overexpression or deficiency of p19 has any effect on DNA repair capacity, we used the unscheduled DNA synthesis assay which reflects cellular ability to repair damage to genomic DNA. Puromycin-selected cells, previously transfected with vector encoding sense or antisense p19 cDNA, were incubated in arginine-free and low-serum medium, in order to arrest cells at G0/G1 and minimize DNA semiconservative synthesis. Cell cultures were irradiated with $8 \mathrm{~mJ} / \mathrm{cm}^{2} \mathrm{UV}$, and ${ }^{3} \mathrm{H}$ thymidine incorporation to DNA was measured several times. As shown in Figure 7, p19-overexpressing $\mathrm{SH}-$ SY5Y cells were found to increase DNA repair synthesis by $50 \%$ compared with nonexpressing cells. On the 


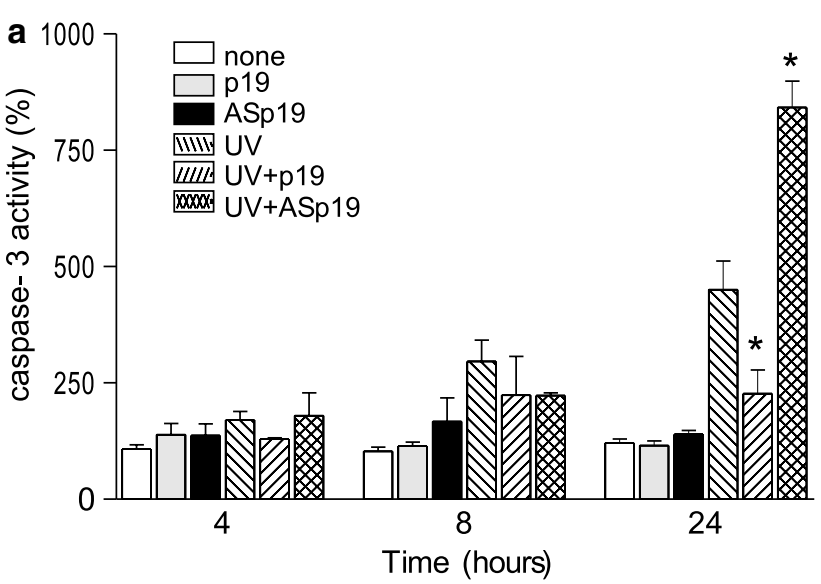

b

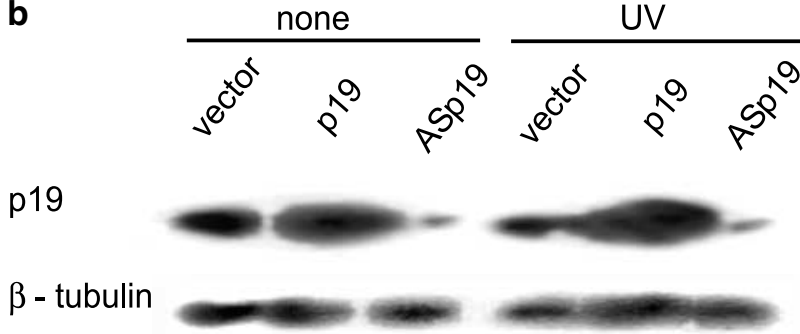

Figure 6 p19 regulates caspase-3 activity induced by UV light. SH-SY5Y cells were transfected with $2 \mu \mathrm{g}$ of the expression vector encoding sense (p19) or antisense p19 (ASp19) cDNA along with $0.5 \mu \mathrm{g}$ of puroBABE. At $24 \mathrm{~h}$ after transfection, cells were treated for an additional $60 \mathrm{~h}$ with puromycin. Resistant cells were irradiated with $8 \mathrm{~mJ} / \mathrm{cm}^{2}$ UV light. (a) At different time points after irradiation, cell lysates were tested for caspase-3 activity. Results are expressed as percentage of caspase- 3 activity with respect to basal activity of cell lysates nontransfected and without UV-treatment measured at time point $4 \mathrm{~h}$, which was set to 100 . Bars represent the mean \pm s.e. of three different experiments performed in duplicate. Students $t$-test was used to compare, samples cotransfected and UV-treated with samples noncotransfected $\left({ }^{*} P<0.05\right)$. (b) Total RNA $(20 \mu \mathrm{g})$ was extracted from irradiated and nonirradiated cells at time point $0 \mathrm{~h}$ and subjected to Northern blot analysis using a ${ }^{32} \mathrm{P}$-labeled probe specific for human p19 mRNA and reprobed for $\beta$-tubulin mRNA. The figure shows a representative autoradiograph of three independent experiments with similar results

contrary, DNA repair synthesis was dramatically reduced in UV-irradiated p19-deficient cells. This reduction of unscheduled DNA synthesis not only indicates that the enhancement of DNA repair results specifically from overexpression of p19, but also that endogenous p19 is necessary to drive a complete response to DNA damage.

\section{p19 negatively regulates apoptosis and increases neuroblastoma cells' ability to repair DNA damage induced by $U V$ irradiation independently of CDK4 interaction}

p19, as the other INK4 members, blocks the progression of the cell cycle by binding to either CDK 4 or CDK6 and inhibiting the action of cyclin D (Roussel, 1999). To check whether p19 interaction with CDK4 is necessary to exert the observed effects on apoptosis and DNA

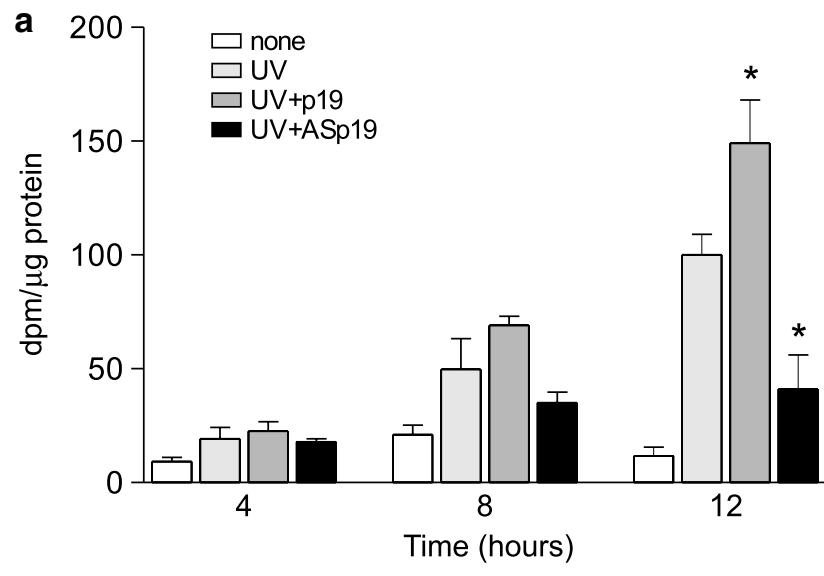

b

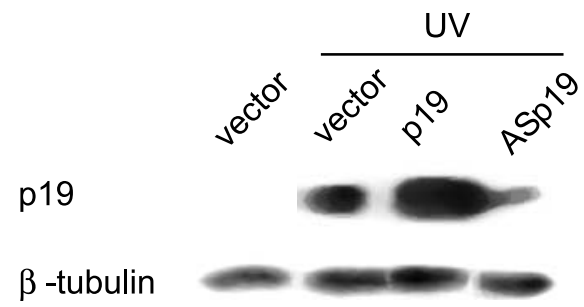

Figure 7 p19 increases the ability of SH-SY5Y to repair UVdamaged DNA. SH-SY5Y cells were transfected with $2 \mu \mathrm{g}$ of the expression vector encoding sense (p19) or antisense p19 (ASp19) cDNA along with $0.5 \mu \mathrm{g}$ of puroBABE. At $24 \mathrm{~h}$ after transfection, regular media was substituted for arginine-free medium containing $1 \%$ fetal bovine serum and cells were treated with puromycin and incubated for an additional $60 \mathrm{~h}$. Resistant cells were irradiated with $8 \mathrm{~mJ} / \mathrm{cm}^{2}$ UV light. (a) After UV irradiation, cells were incubated with $10 \mu \mathrm{Ci}\left[{ }^{3} \mathrm{H}\right]$ thymidine and cell lysates were tested for UDS at different time points. Bars represent the mean \pm s.e. of four different experiments performed in duplicate. Students $t$-test was used to compare samples cotransfected and UV-treated with samples noncotransfected $\left({ }^{*} P<0.05\right)$. (b) Total RNA $(20 \mu \mathrm{g})$ was extracted from irradiated and nonirradiated cells at time point $8 \mathrm{~h}$ and subjected to Northern blot analysis using a ${ }^{32} \mathrm{P}$-labeled probe specific for human p19 mRNA and reprobed for $\beta$-tubulin mRNA. The figure shows a representative autoradiograph of three independent experiments with similar results

repair, we performed transfection experiments coexpressing wt CDK4 or a mutant version CDK4R24C together with expression vector coding for p19 cDNA. This mutant CDK4 variant has a point mutation (replacement of $\operatorname{Arg} 24$ by Cys) in the first coding exon, and renders a variant that has full kinase activity but does not bind to and is therefore not inhibited by INK4 proteins (Sotillo et al., 2001). The rationale was that if p19 exerts its action on DNA repair and apoptosis associated with CDK4, the combined overexpression of p19 and wt CDK4 should drive to an increase of the observed effects, while the combined overexpression of p19 and a mutant CDK4 defective in INK4 binding would attenuate them. On the contrary, if p19 exerts its effects in a CDK4-independent manner, the increase on DNA repair and the decrease on apoptosis observed with p19 overexpression should be accentuated in the presence of such CDK4 mutant. 
The results depicted in Figure 8a show that wt CDK4 overexpression caused a potentiation of the UVmediated induction of caspase-3 activity; this potentiation was even larger in cells overexpressing the mutant CDK4R24C. We next analysed the effect of combined expression of p19 and CDK4 in cells irradiated with UV light. Importantly, the induction of caspase- 3 activity in response to UV radiation in cells overexpressing p19 was entirely different depending on the CDK4 context. In this regard, p19 co-expression in cells overexpressing wt CDK4 did not modify caspase-3 activity, as evaluated by the ratio UV + CDK $4 w t+p 19 /$ $\mathrm{UV}+\mathrm{CDK} 4 \mathrm{wt}=0.96$. Conversely, in the context of mutant CDK4R24C overexpression, p19 co-expression caused an important reduction of UV-mediated induction of caspase-3 activity (UV + CDK4R24C + p19/ $\mathrm{UV}+\mathrm{CDK} 4 \mathrm{R} 24 \mathrm{C}=0.38$ ). Next, we sought to determine the effect of wt and mutant CDK4R24C on the DNA repair ability of UV-irradiated SH-SY5Y cells with endogenous or overexpressed levels of p19. To address this question, we performed unscheduled DNA synthesis assays in cell cultures parallel to those used to evaluate caspase activity. As shown in Figure 8b, the ability of p19 to enhance genomic DNA repair in response to UV irradiation was impaired in $\mathrm{wt}$ CDK4-overexpressing cells (UV + CDK4wt + p19/ $\mathrm{UV}+\mathrm{CDK} 4 \mathrm{wt}=0.78)$. However, DNA synthesis associated with UV damage increased twice by p19 coexpression in cells overexpressing mutant CDK4R24C $(\mathrm{UV}+\mathrm{CDK} 4 \mathrm{R} 24 \mathrm{C}+\mathrm{p} 19 / \mathrm{UV}+\mathrm{CDK} 4 \mathrm{R} 24 \mathrm{C}=2.08)$.

These results indicate that wt CDK4, but not INK4binding defective mutant CDK4R24C, prevents p19 to enhance UV-dependent DNA repair and reduce apoptosis, and strongly suggest that p19 exerts the mentioned effects in a CDK4-independent manner.

Figure 8 p19 exerts its effects independently of CDK4 interaction. SH-SY5Y cells were transfected with $2 \mu \mathrm{g}$ of the expression vector encoding p19 cDNA, and cotransfected or not with $2 \mu \mathrm{g}$ of the indicated expression vector for wt or mutant (R24C) CDK4 along with $0.5 \mu \mathrm{g}$ of puroBABE. (a) At $24 \mathrm{~h}$ after transfection, cells were treated for additional $60 \mathrm{~h}$ with puromycin. Resistant cells were irradiated with $8 \mathrm{~mJ} / \mathrm{cm}^{2}$ UV light. Cell lysates were tested for caspase- 3 activity at 0 and $24 \mathrm{~h}$ postirradiation. Results are expressed as percentage of caspase-3 activity with respect to basal activity of cell lysates nontransfected and without UV treatment, which was set to 100 . Bars represent the mean \pm s.e. of three different experiments performed in duplicate. Student's $t$-test was used to compare, samples cotransfected with a CDK4 version and p19 with samples transfected with the respective CDK4 alone $\left({ }^{*} P<0.05\right)$. (b) At $24 \mathrm{~h}$ after transfection, regular media was substituted for arginine-free medium containing $1 \%$ fetal bovine serum and cells were treated with puromycin and incubated for an additional $60 \mathrm{~h}$. Resistant cells were irradiated with $8 \mathrm{~mJ} / \mathrm{cm}^{2} \mathrm{UV}$ light and, immediately, incubated with $10 \mu \mathrm{Ci}\left[{ }^{3} \mathrm{H}\right]$ thymidine for $12 \mathrm{~h}$ and then cell lysates were tested for UDS. Bars represent the mean \pm s.e. of three different experiments performed in duplicate. Student's $t$-test was used to compare samples cotransfected with a CDK4 version and 19 with samples transfected with the respective CDK4 alone $(* P<0.05)$. (c) Total RNA $(20 \mu \mathrm{g})$ was extracted from the cells treated as in (a) and subjected to Northern blot analysis using a ${ }^{32}$ P-labeled probe specific for human p19 mRNA and reprobed for CDK4 and $\beta$-tubulin mRNA. The figure shows a representative autoradiograph of three independent experiments with similar results
In order to confront the above hypothesis, we performed a set of experiments in the Rb-deficient cell line, Saos-2. Several authors have demonstrated that overexpressed INK4 proteins arrest the cell cycle in G1 phase in a manner that depends on Rb integrity (Lukas et al., 1995; Guan et al., 1996; Sherr and Roberts, 1999). So, in this human osteosarcoma-derived cell line, overexpression of any INK4, including p19, would not cause a G1 arrest as it does in Rb-proficient cells (e.g. SH-SY5Y). The reasoning behind this experiment was whether p19 would also be able to improve repair of UV-induced DNA damage and diminish apoptosis in Rb-deficient cells; like Saos-2, this would indicate a dissociation among these uncover functions of p19 and those related with CDK4/6 inhibition. Experiments whose results are depicted in Figure 9a show that
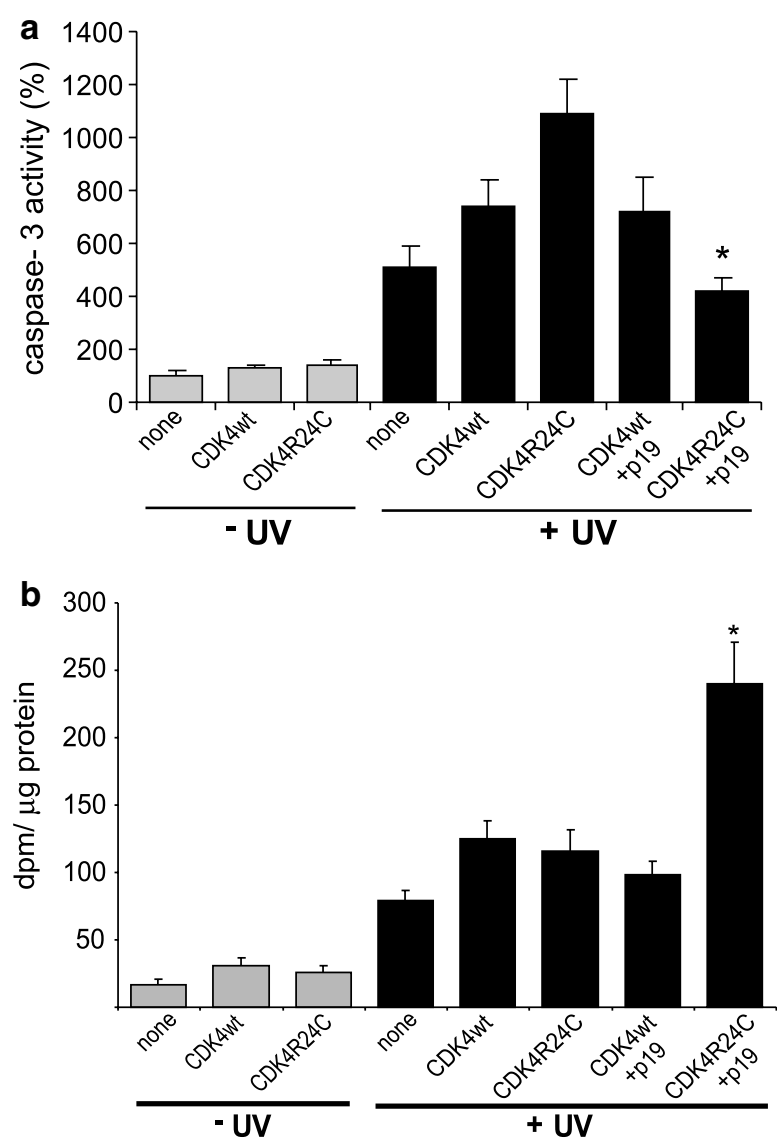

C

UV

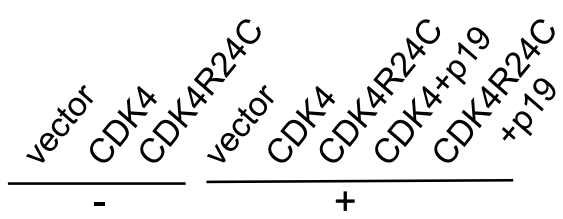

CDK4

p19

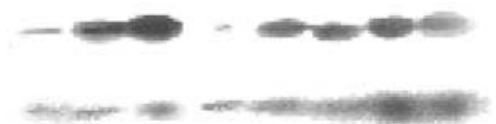

$\beta-$ tubulin 

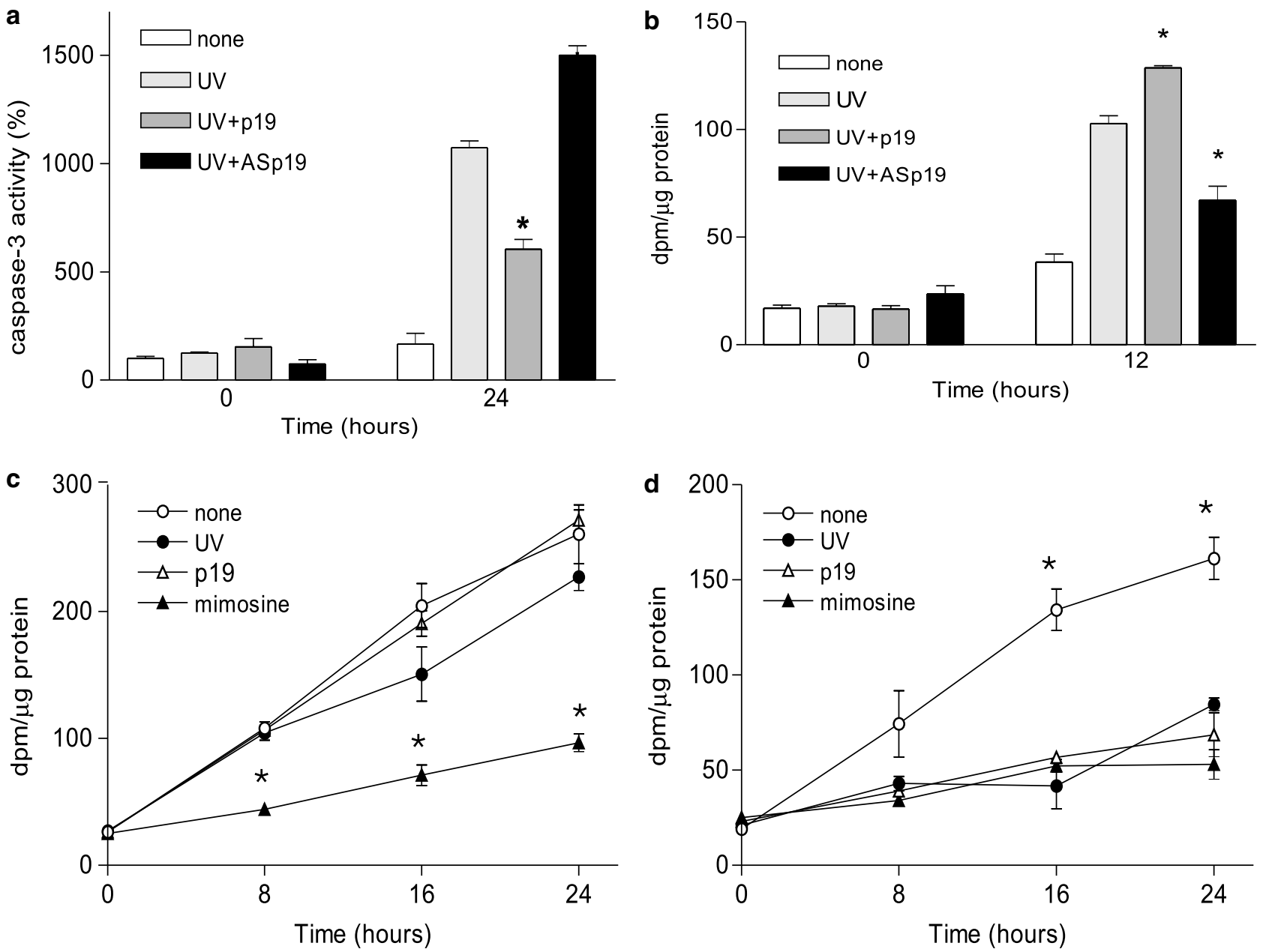

Figure 9 Effects of p19 in Rb-deficient Saos-2 cells. (a) Saos-2 cells were transfected with $2 \mu \mathrm{g}$ of the expression vector encoding sense (p19) or antisense p19 (ASp19) cDNA along with $0.5 \mu \mathrm{g}$ of puroBABE. At $24 \mathrm{~h}$ after transfection, cells were treated for an additional $60 \mathrm{~h}$ with puromycin. Resistant cells were irradiated with $8 \mathrm{~mJ} / \mathrm{cm}^{2} \mathrm{UV}$ light. Immediately and $24 \mathrm{~h}$ after irradiation, cell lysates were tested for caspase- 3 activity. Results are expressed as percentage of caspase-3 activity with respect to basal activity of cell lysates noncotransfected and without UV treatment measured at time point $0 \mathrm{~h}$, which was set to 100 . Bars represent the mean \pm s.e. of three different experiments performed in duplicate. Students $t$-test was used to compare, samples cotransfected and UV-treated with samples noncotransfected $\left({ }^{*} P<0.05\right)$. (b) Saos- 2 cells were transfected with $2 \mu \mathrm{g}$ of the expression vector encoding sense (p19) or antisense p19 (ASp19) cDNA along with $0.5 \mu \mathrm{g}$ of puroBABE and treated for UDS assay as described in legend for Figure 7a. Bars represent the mean \pm s.e. of three different experiments performed in duplicate. Student's $t$-test was used to compare samples cotransfected and UVtreated with samples noncotransfected $\left({ }^{*} P<0.05\right)$. Saos-2 (c) or SH-SY5Y (d) cells were transfected with $0.5 \mu \mathrm{g}$ of puroBABE and with $2 \mu \mathrm{g}$ of the expression vector encoding sense (p19) cDNA as indicated. At $24 \mathrm{~h}$ after transfection, cells were treated for an additional $36 \mathrm{~h}$ with puromycin. At this time, cells were treated with $500 \mu \mathrm{M}$ mimosine as indicated and incubated for an additional $24 \mathrm{~h}$ in the presence of puromycin. Resistant cells were irradiated with $8 \mathrm{~mJ} / \mathrm{cm}^{2}$. At this time, all cultures were incubated with $1 \mu \mathrm{Ci}\left[{ }^{3} \mathrm{H}\right]$ thymidine and tested for nucleotide incorporation at different time points. Bars represent the mean \pm s.e. of three different experiments. Student's $t$-test was used to compare different samples with basal ones at the same time point. $\left({ }^{*} P<0.05\right)$

caspase-3 activity was reduced in overexpressing p19 Saos-2 cells, whereas a significant increment was observed in cells transfected with antisense p19. In addition, the ability of Saos-2 cells to repair UV-induced DNA damage was markedly improved by p19 overexpression and, conversely, this repair capacity was partially impaired in p19-deficient Saos-2 cells (Figure 9b). The above results show that, upon DNA damage, p19 displays a very similar response in both SH-SY5Y (Rb-proficient) and Saos-2 (Rb-deficient) cell lines. The p19 mRNA levels in selected transfectants were checked as in experiments depicted in Figures $6 \mathrm{~b}$ and $7 b$ (data not shown).

Next, we evaluated the effect of p19 on both SHSY5Y and Saos-2 cell proliferation. Thymidine incorporation assays show that, as observed before, SHSY5Y cell proliferation is strongly impaired in p19overexpressing cells (Figure 9d). On the contrary, p19 was unable to cause a G1 arrest when it was overexpressed in Rb-deficient Saos-2 cells (Figure 9c). However, Saos-2 cell, as well as SH-SY5Y, entry into $\mathrm{S}$-phase was blocked by incubation with mimosine, a 
ribonucleotide reductase inhibitor. Together, these results demonstrate that the mechanism by which $\mathrm{p} 19$ improves DNA repair and diminishes UV-triggered apoptosis is independent of its role as cell cycle regulator.

Causal relationship between enhanced $D N A$ repair and diminished apoptosis in UV-treated cells overexpressing p19

To further strengthen the hypothesis that links p19 effects on DNA repair and apoptosis, unscheduled DNA synthesis and caspase-3 activity assays were undertaken in UV-treated neuroblastoma cells in the presence of F11782, a nucleotide excision repair (NER) inhibitor (Barret et al., 2002). The results obtained from UDS assays show, as it was already observed in previous experiments (Figure 7), that in p19-overexpressing SHSY5Y cells DNA repair after UV irradiation was increased (Figure 10a). In addition, F11782 treatment was effective to achieve NER inhibition since DNA synthesis associated with UV damage was not distinguishable from DNA synthesis in nonirradiated cells. We next determined caspase-3 activity in SH-SY 5Y cells in the presence or in the absence of F11782. UVirradiated cells incubated without NER inhibitor showed an elevated caspase- 3 activity that was partially impaired in cells with p19 overexpression. Remarkably, the UV-mediated induction of caspase-3 activity was higher in the presence of F11782 and, in this case, p19 overexpression was unable to diminish it (Figure 10b). These results point out DNA repair as the main target of p19 action, and indicate that diminished apoptosis is a downstream causal event.

\section{Discussion}

The genetic instability driving tumorigenesis is fuelled by DNA damage and by errors made by the DNA replication. The cell cycle machinery somehow senses genome injury and arrests at specific checkpoints in G1, $\mathrm{S}, \mathrm{G} 2$, and $\mathrm{M}$ to allow repair of lesions before they are converted into permanent mutations (Hoeijmakers, 2001; Sandal, 2002). When damage is too significant, a cell may opt for the ultimate mode of rescue by initiating apoptosis at the expense of a whole cell (Hahn and Weinberg, 2002; Martin, 2003). In the previous years the hypothesis that upon DNA damage the cell organizes an integrated response not only by the classical DNA repair mechanisms but also involving mechanisms of replication, transcription, chromatin structure dynamics, cell cycle progression, and apoptosis has been delineated. In the context of this new vision of the control of genomic stability, we propose that, in addition to its role as cell cycle inhibitor, p19 is involved in maintenance of DNA integrity.

The present study had two major aims. The first was to analyse the potential role of $\mathrm{p} 19$, in the cellular response to DNA damage. The second was to study the ability of p19 to improve the capacity of cells to repair
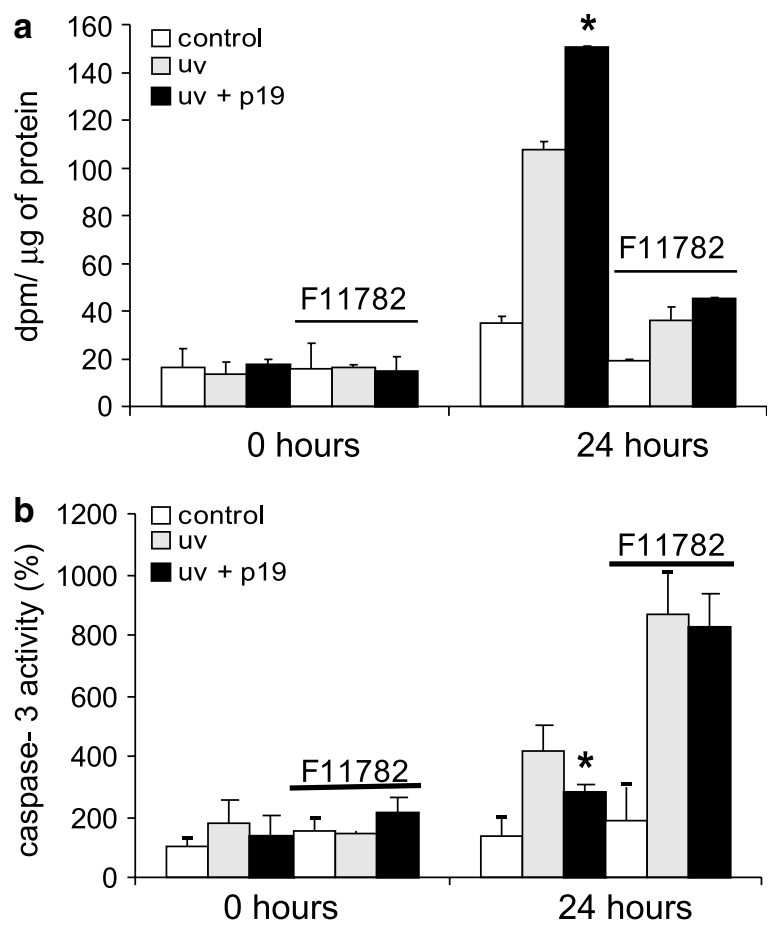

Figure 10 Relationship between enhanced DNA repair and diminished apoptosis in UV-treated cells overexpressing p19. SHSY5Y cells were transfected with $2 \mu \mathrm{g}$ of the expression vector encoding p19 cDNA or empty vector along with $0.5 \mu \mathrm{g}$ of puroBABE. (a) At $24 \mathrm{~h}$ after transfection, the regular media was substituted for arginine-free medium containing $1 \% \mathrm{FCS}$ and cells were treated with puromycin and incubated for an additional $60 \mathrm{~h}$ Resistant cells were treated with $50 \mu \mathrm{M}$ of the NER inhibitor F11782 and after $30 \mathrm{~min}$ cells were irradiated with $8 \mathrm{~mJ} / \mathrm{cm}^{2} \mathrm{UV}$ light and incubated with $10 \mu \mathrm{Ci}\left[{ }^{3} \mathrm{H}\right]$ thymidine. Immediately and $12 \mathrm{~h}$ later, cell lysates were tested for UDS. Bars represent the mean \pm s.e. of three different experiments performed in duplicate. Student's $t$-test was used to compare samples cotransfected and UV-treated with samples noncotransfected $\left({ }^{*} P<0.05\right)$. (b) At $24 \mathrm{~h}$ after transfection, cells were treated for an additional $60 \mathrm{~h}$ with puromycin. Resistant cells were treated with $50 \mu \mathrm{M}$ of the NER inhibitor F11782 and after $30 \mathrm{~min}$ the cells were irradiated with $8 \mathrm{~mJ} / \mathrm{cm}^{2}$ UV light. Immediately and $24 \mathrm{~h}$ after irradiation, cell lysates were tested for caspase-3 activity. Results are expressed as percentage of caspase- 3 activity with respect to basal activity of cell lysates noncotransfected and without UV treatment measured at time point $0 \mathrm{~h}$, which was set to 100 . Bars represent the mean \pm s.e. of three different experiments performed in duplicate. Student's $t$ test was used to compare samples cotransfected and UV-treated with samples noncotransfected $(* P<0.05)$

UV-damaged DNA. To achieve these ends, we used neuroblastoma cells that express p19. As it has been reported by other authors (Hirai et al., 1995; Guan et al., 1996), p19 mRNA and protein present a periodic oscillation during the SH-SY5Y cell cycle. This p19 feature appears to be distinct from the remaining INK4. Its expression is low in $\mathrm{Go} / \mathrm{G} 1$, and peaks in late $\mathrm{G} 1$ and $\mathrm{S}$ phase. The periodicity of p19 protein during the cell cycle was reported to be determined by the ubiquitin/ proteasome-dependent degradation mechanism, allowing the protein abundance to follow the changes in its mRNA expression (Thullberg et al., 2000). However, the events that determine the cyclic expression of p19 gene remain elusive. 
We found that exposure of neuroblastoma cells to UV radiation induces changes on p19 cellular status including transcriptional activation and nuclear translocation. After $24 \mathrm{~h}$ irradiation, p19 mRNA and protein levels were greatly increased. This p19 upregulation appears to be a general phenomenon since it was observed in all cell lines tested, including those like HeLa cells that show not detectable p19 expression (Hirai et al., 1995). This increase cannot be only due to the augmented G1-phase population as a consequence of UV treatment, since 4-5-fold p19 mRNA induction was observed. Other authors have reported that in response to UV radiation the level of p16 increases in cervical cancer HeLa and melanoma A2058 cell lines (Milligan et al., 1998). However, we were not able to detect UV-mediated changes in INK4 expression other than p19. A possible molecular basis of this different behavior appears to lie in distinct, tissue-specific patterns of INK4 expression (Zindy et al., 1997a). Furthermore, their transcription is known to respond differentially to diverse stimuli. Induction of $\mathrm{p} 15 \mathrm{INK} 4 \mathrm{~b}$ in response to transforming growth factor $\beta$, or upregulation of p16INK 4a following some oncogenic stimuli, or increased expression of p18INK4c associated with the antiproliferative action of interleukin-6, are among other examples of such differential transcriptional regulation (Serrano, 1997; Ruas and Peters, 1998). In this regard, p19 expression has recently begun to be studied and regulation by transcription factor $\mathrm{Sp} 1$ and histone deacteylase inhibitors has been reported (Matsuzaki et al., 2002; Yokota et al., 2004). In silico analysis of the proximal $5^{\prime}$ regulatory region of $p 19$ gene reveals a high homologous binding site for NF- $\kappa \mathrm{B}$ transcription factor. In addition, we observed that RelA-transfected fibroblasts display an increase p19 mRNA level (unpublished data). The transcription factor NF- $\kappa \mathrm{B}$ is a critical immediate early response gene involved in modulating cellular responses and apoptosis following diverse environmental injuries (Fan et al., 2002; Wu et al., 2004). Common activating stimuli including lipopolysaccharide, hypoxia, or UV induce $\mathrm{NF}-\kappa \mathrm{B}$ translocation to the nucleus upon activation and could explain UV-mediated p19 induction.

The subcellular distribution of p19 in SH-SY5Y was also examined by indirect immunofluorescence microscopy. Previous studies in other cell lines (Hirai et al., 1995; Guan et al., 1996), as well as those presented here, demonstrate that $\mathrm{p} 19$ has a cytoplasmic location. We also observed that, following UV irradiation, p19 is translocated into the nucleus with a maximum between 36 and $48 \mathrm{~h}$. The import of proteins into the nucleus is not a constitutive process, and appears to be modulated in response to external stimuli, cell cycle, and development. A variety of genotoxics affects multiple aspects of cellular physiology, and an important part of the response to cellular stress involves the translocation of stress-responsible factors from the cytoplasm to the nucleus. However, how these factors are translocated into the nucleus in response to stress or how the nuclear transport pathways are regulated in injured cells is unclear (Miyamoto et al., 2004). Computer-aided analysis shows that p19 does not contain the standard basic monopartite or bipartite nuclear localization signal (NLS) found in most nuclear proteins (Dingwall and Laskey, 1991). Even though there is no known NLS within the p19 sequence, this does not by itself preclude a nonstandard NLS. An essential regulatory mechanism for subcellular localization of proteins involves the direct phosphorylation of the transported protein (Mattaj and Englmeier, 1998; Lim et al., 2003). In this regard, it has been reported that p19 is the unique INK4 capable of being phosphorylated in vivo in two conserved serines residues (Thullberg et al., 2000). Such a series of phosphorylation events on phylogenetically conserved residues, a feature unique in the INK4 family, emerges as an attractive potential mechanism to control nuclear transport of p19 protein.

The above results lead us to consider that p19 may be a part of mammalian stress signal mechanism being initiated in response to DNA-damaging agents, playing a role in the maintenance of DNA integrity. The present work provides strong evidences that UV-induced apoptosis of human neuroblastoma cells is negatively regulated by $\mathrm{p} 19$. Using flow-cytometric analysis, we show that p19-overexpressing SH-SY5Y cells are more resistant to apoptosis, following treatment with UV light, than their counterparts displaying nondetectable levels of p19 protein. These results were supported by those obtained from DNA fragmentation and caspase-3 activity assays. Apoptosis is the consequence of a genetically determined cell death program that can be initiated by a number of stimuli such as growth factor withdrawal, signaling through apoptotic receptors, or cell-damaging stress. Induction of apoptosis by DNAdamaging agents plays a central role in the elimination of genetically altered cells, contributing to the inhibition of tumor development (Johnstone et al., 2002; Norbury and Zhivotovsky, 2004). Loss of apoptosis, on the other hand, undoubtedly plays a major role in tumorigenesis (Igney and Krammer, 2002). Recently, it has been reported that other INK4, the tumor suppressor p16, has a similar protective effect on UV-induced apoptosis in osteosarcoma cells. The authors suggest that p16 negatively controls UV-induced apoptosis by downregulating the level of the apoptosis agonist Bax protein (Al-Mohanna et al., 2004). DNA damage induced by UV light is known to be responsible for UV-induced genotoxicity. However, its role in triggering apoptosis is still unclear, although several evidences suggest that UV-induced apoptosis is elicited by the nonrepaired photolesions. This suggests a direct link between apoptosis and DNA repair (Dunkern et al., 2001; Norbury and Zhivotovsky, 2004).

An attractive hypothesis explaining the antiapoptotic effect of p19 would involve the immediate early gene Nur77, which encodes an orphan nuclear receptor, that is rapidly induced by various stress stimuli, including DNA damage. It was initially suggested that DNA binding and transactivation by Nurr77 might be required for its proapoptotic effect. More recent data show that, although normally nuclear, in response to genotoxics Nurr77 was translocated to the cytosol where 
it was implicated in the release of mitochondrial cytochrome $c$ (Wilson et al., 2003; Norbury and Zhivotovsky, 2004). It has been reported that p19 can interact with Nurr77 in T-cell hybridomas (Chan et al., 1995; Ruas and Peters, 1998). Therefore, the UVmediated p19 induction could diminish apoptosis by sequestering Nurr77 and blocking its proapoptotic effects. On the other hand, it has been reported that dominant negative CDK4 and 6 as well as CKIs p16 and p27 protect cortical neurons from apoptosis induced by DNA damage, suggesting that the activities of the corresponding endogenous CDKs should be elevated in dying neurons due to induced cyclin D1 expression (Park et al., 1998). In this case, p19 could interact with CDK4 and 6 and block their augmented activity, thus counteracting the apoptotic signals. Nevertheless, cyclin D induction after DNA damage appears to be not a wide-range response, since other authors have reported a diminished cyclin D level in several cell lines that have been exposed to a variety of genotoxic insults, including UV light (Shapiro et al., 1998). Finally, p19 could exert its effect directly on DNA repair by increasing the efficiency of the mechanisms implied in photolesions removal and, in consequence, diminish the number of cells in which apoptosis has been triggered.

Our results strongly support the latter hypothesis, since overexpression of $\mathrm{p} 19$ improves repair of UVinduced DNA damage and, moreover, p19-transiently defective cells were deficient in repairing the UV genotoxic effect. NER is the DNA repair mechanism responsible for the removal of bulky DNA adducts produced by UV light and by a number of environmental carcinogens (Friedberg, 2001; Sancar et al., 2004). NER comprises two pathways: transcriptioncoupled repair, generally the faster of two, which removes DNA damage in transcribable regions of the genome, and global genomic repair, which eliminates DNA damage in the rest of the chromatin (Rubbi and Milner, 2003). We assessed the DNA-repair capacity of neuroblastoma cells, by the UDS assay. In this regard, results from UDS experiments suggest that p19 would act on the whole damaged DNA, since UDS detection is highly suitable for quantifying repair synthesis after the excision step over the entire mammalian genome, rather than at a specific locus. Experiments using the NER inhibitor F11782 provide additional sustain for DNA repair as the major target of p19 effect. The F11782 is a novel dual inhibitor of topoisomerases I and II that was identified as a potent inhibitor of NER, predominantly at the incision rather than at the repair synthesis step (Barret et al., 2002). In such experiments, NER inhibition causes a great increase in UV-induced apoptosis even in p19-overexpressing cells. These results are consistent with a model proposing that p19 protects neuroblastoma cells from undergoing apoptosis in response to UV damage, by allowing a more efficient repair of DNA damage.

Thus, how does p19 improve DNA repair after UV damaging? One simple explanation of these findings would be that, after DNA damage, increased amounts of p19 bind to CDK4 and CDK6 arresting cells in G1 phase, which in turn would permit a more efficient repair of the UV-induced injury. In this regard, p16 has been implicated in a G1 arrest checkpoint in response to DNA damage (Shapiro et al., 1998). However, our data indicate that this is not the case. The experiments using wt and mutant CDK4 demonstrate that the larger extent of DNA repair in cells that overexpress p19 was observed in the presence of a constitutively active CDK4 that does not bind the INK4 protein. These results are not reliable with the above hypothesis. Rather, they suggest a CDK4-independent role of p19, not related with its antiproliferative capacity. Results obtained in the Rb-deficient Saos-2 cells provide additional support to this interpretation. In these cells, as well as in SH-SY5Y cells, p19 overexpression was capable of improving DNA repair and diminishing apoptosis. Nevertheless, in Saos-2 cells, unlike SHSY 5Y, p19 was unable to arrest cell proliferation. These data sustain that the role of p19 as cell cycle regulator is dissociated from DNA repair functions.

Two systems are essential in humans for genome integrity, DNA repair and apoptosis. Cells that are defective in DNA repair tend to accumulate excess DNA damage. Cells defective in apoptosis tend to survive with excess DNA damage and thus allow replication past DNA damages, causing mutations leading to carcinogenesis. It has recently become apparent that key proteins which contribute to cellular survival by acting in DNA repair become executioners in the face of excess DNA damage. The maintenance of a switching mechanism that shifts the cell from DNA repair to apoptosis, as appropriate in the presence of excessive DNA damage, appears to be of central importance for avoiding progression to cancer. The default mechanism of apoptosis prevents clonal expansion of cells in which accumulated unrepaired damage would lead to mutation and to carcinogenesis.

Therefore, a commitment should exist between the time window to allow proper DNA repair and to trigger cell death mechanisms to avoid an increase in the mutation load causing genomic instability, characteristic of cancer progression (Lengauer et al., 1998; Bernstein et al., 2002). This is particularly true in postmitotic neurons from the central nervous system, where neuronal death causes an irreplaceable loss. In addition, neuronal cell death can occur abnormally by its timing, its causes, or its extent. This is obviously of particular importance when the human nervous system is concerned, where extensive cell death is observed in neurodegenerative diseases and after stroke or trauma (Connor and Dragunow, 1998; Yuan and Yankner, 2000). In this scenario, the action of proteins allowing a more robust response against DNA injury and, in consequence, avoiding excessive apoptosis is highly desirable. The described ability of p19 in maintaining genomic integrity would adjust to this premise. The fact that central nervous system is one tissue where p19 expression is relatively important and that high levels of p19 are present in developing and adult postmitotic neurons correlate in support. 
In summary, we demonstrate that, in response to UV irradiation, p19 gene expression in neuroblastoma cells is augmented and that increased p19 level improves DNA repair. These changes are accompanied by a marked diminution in UV-induced apoptosis. This paper describes a new role for p19 as contributor to the mechanisms implicated in the maintenance of genomic stability in a manner that is independent of its ability to inhibit CDK4 and 6. Therefore, it becomes apparent that p19 would participate in prevention of carcinogenesis. Studies designed to determine the precise role of p19 in DNA repair and the participation of p19 in response to another genotoxics are in progress.

\section{Materials and methods}

\section{Plasmid generation}

The entire coding sequence of human p19 was amplified by PCR from a human brain cDNA library generously provided by Dr Enzo Lalli (Strasbourg) using the appropriate primers designed with EcoRI and BamHI sites. Forward primer: 5'-GGGAATTCATGCTGCTGGAGGAGGTTCGC-3' corresponds to the first 21 nucleotides and reverse primer: 5'-GGGGATCCTCACAGCGGGGCCACCATGTG-3' to the last 21 nucleotides of $\mathrm{p} 19$ coding region. The p19 expression plasmid (pSG5p19) was constructed by cloning the EcoRI and BamHI PCR fragment into pSG5 vector. The expression plasmid harboring the antisense p19 cDNA (pSG5p19AS) was constructed following the same procedure using $5^{\prime}$-GGGGATCCATGCTGCTGGAGGAGGTTCGC- $3^{\prime}$ as forward primer and $5^{\prime}$-GGGAATTCACAGCGGGGC CACCATGTG- $3^{\prime}$ as reverse primer. The fidelity of the generated plasmids was checked by DNA sequencing.

\section{Cell cultures and transfections}

The human neuroblastoma cell lines SH-SY5Y and IMR-32 and the mouse neuroblastoma cell line Neu-2a were grown in Dulbecco's minimum essential medium (45\%) and HAM F-12 $(45 \%)$ (Invitrogen) supplemented with $10 \%$ fetal calf serum (FCS), $100 \mathrm{U} / \mathrm{ml}$ penicillin, $100 \mu \mathrm{g} / \mathrm{ml}$ streptomycin, $30 \mu \mathrm{g} / \mathrm{ml}$ gentamicin, $2 \mathrm{~mm}$ glutamine (Invitrogen), and $1 \mathrm{mM}$ sodium pyruvate at $37^{\circ} \mathrm{C}$ in $5 \% \mathrm{CO}_{2}$. The human hepatoma HepG2 cells were grown in minimum essential medium supplemented with $10 \%$ FCS, $100 \mathrm{U} / \mathrm{ml}$ penicillin, $100 \mu \mathrm{g} / \mathrm{ml}$ streptomycin, $30 \mu \mathrm{g} / \mathrm{ml}$ gentamicin, and $2 \mathrm{~mm}$ glutamine at $37^{\circ} \mathrm{C}$ in $5 \% \mathrm{CO}_{2}$. The human epithelial HeLa, hamster fibroblast BHK-21, and human osteosarcoma-derived Saos-2 cell lines were maintained in Dulbecco's minimum essential medium and supplemented as HepG2 cells. Transfections were performed with Lipofectamine 2000 reagent (Invitrogen) following the manufactureŕs protocol. Cell lines were cotransfected with $2 \mu \mathrm{g}$ of pSG5p19 or pSG5p19AS along with $0.5 \mu \mathrm{g}$ of puroBABE. When indicated, cells were cotransfected with $2 \mu \mathrm{g}$ of pSG5p19 and $2 \mu \mathrm{g}$ of expression vector for CDK4wt or mutant CDK4R24C (a generous gift of Patrick O'Connor, Bethesda). Puromycin (Sigma) $2.5 \mu \mathrm{g} / \mathrm{ml}$ was added $24 \mathrm{~h}$ after transfection. Puromycin-resistant cells were utilized $60 \mathrm{~h}$ later.

\section{UV irradiation}

Exponentially growing cells were trypsinized and seeded in 35$\mathrm{mm}$ plates at $50-60 \%$ confluence. At $24 \mathrm{~h}$ after plating, cells were irradiated in open dishes with UV $8 \mathrm{~mJ} / \mathrm{cm}^{2}, 254 \mathrm{~nm}$ (range 240-280 nm) at room temperature from a Philips ultraviolet lamp (TUV15WG15T8) calibrated to deliver $0.25 \mathrm{~mJ} / \mathrm{cm}^{2} \mathrm{~s}$. Following exposure, the medium was replaced and cells were incubated in a $5 \% \mathrm{CO}_{2}$ incubator at $37^{\circ} \mathrm{C}$ along times indicated in each case. For each experiment, control cells were treated identically, except for the exposure to UV light.

\section{Cell count and MTT assay}

Cell viability was assessed by 3-[4,5-dimethylthiazol-2-yl]-2,5diphenyltetrazolium bromide (MTT) assay. Exponentially growing cells $\left(2 \times 10^{5}\right.$ cells/well $)$ were seeded in six-well plates and incubated for $24 \mathrm{~h}$. Cells were treated with the indicated UV doses and cell survival evaluated at different times by replacing the culture media with $1 \mathrm{ml}$ of fresh medium containing MTT (Sigma) to a final concentration of $1 \mathrm{mg} / \mathrm{ml}$ and incubated at $37^{\circ} \mathrm{C}$. After $4-6 \mathrm{~h}$ of incubation, the medium and MTT were removed and $500 \mu \mathrm{l}$ of isopropanol was added to dissolve the precipitate of reduced MTT. Plates were shaken for $15 \mathrm{~min}$ and the absorbance in the solvent was determined at $570 \mathrm{~nm}$. The background was subtracted by using a dualwavelength setting of 570 and $650 \mathrm{~nm}$. Controls included untreated cells and medium alone. In parallel, the number of viable cells were determined by strip counting.

\section{$\left[{ }^{3} \mathrm{H}\right]$ thymidine incorporation}

Cells were grown on six-well plates $\left(2 \times 10^{5}\right.$ cells/well $)$ in complete medium with $10 \%$ fetal bovine serum. Immediately after treatment, cells were incubated with $1 \mu \mathrm{Ci} / \mathrm{ml}\left[{ }^{3} \mathrm{H}\right]-$ thymidine $(81 \mathrm{Ci} / \mathrm{mmol}$ ) (Amersham Biosciences) for $6 \mathrm{~h}$. Cells were washed three times with cold phosphate-buffered saline (PBS), harvested, and centrifuged at $3000 \mathrm{~g}$ for $5 \mathrm{~min}$. The cellular pellet was lysed with $5 \%$ trichloroacetic acid (TCA) for $30 \mathrm{~min}$, centrifuged and washed twice with cold water. The pellet was resuspended in $150 \mu \mathrm{l} 1 \mathrm{M} \mathrm{NaOH}$ for $1 \mathrm{~h}$ at room temperature. The incorporated radioactivity was quantified by scintillation counting and DNA synthesis estimated as $\mathrm{dpm} / \mu \mathrm{g}$ protein.

\section{RNA isolation and Northern blot analysis}

Total cellular RNA was isolated from cultured cells according to Chomczynski and Sacchi (1987). The yield and purity of RNA samples were assessed by absorbance at $260 \mathrm{~nm}$ and the ratio of absorbance at 260 and $280 \mathrm{~nm}$, respectively. For Northern blot analysis, $20 \mu \mathrm{g}$ of total RNA was denaturated, electrophoresed in 1\% glyoxal-agarose gels, and transferred to nylon membranes (Hybond, Amersham Biosciences). The membranes were sequentially hybridized with ${ }^{32} \mathrm{P}$-labeled probes to human $\mathrm{p} 19, \beta$-tubulin and/or other probes as indicated in each experiment. To detect p19 mRNA, a 24-mer oligodeoxynucleotide was synthesized complementary to bases +3 to +26 of human p19 mRNA (Newton Bishop et al., 1999).The oligodeoxynucleotide was purified and $5^{\prime}$-end labeled using $\left[\gamma^{-32} \mathrm{P}\right] \mathrm{ATP}$ and $\mathrm{T}_{4}$ polynucleotide kinase. The resulting probe had a specific activity of about $4-6 \times 10^{3} \mathrm{cpm} /$ fmol. Hybridization was carried out overnight at $68^{\circ} \mathrm{C}$ in the same prehybridization solution by adding the ${ }^{32} \mathrm{P}$-labeled oligodeoxynucleotide $\left(4 \times 10^{5} \mathrm{cpm} / \mathrm{cm}^{2}\right)$ as previously described (Varone et al., 1999). To detect $\beta$-tubulin and other mRNAs, the corresponding cDNA was labeled by random priming using $\left[\alpha-{ }^{32} \mathrm{P}\right] \mathrm{CTP}$ and Klenow to a specific activity of about $5 \times 10^{8} \mathrm{cpm} / \mu \mathrm{g}$. Membranes were stripped, prehybridized, hybridized, and washed in standard conditions as described before (Scassa et al., 2004). The membranes were 
then exposed and scanned onto a Bio-Imaging Analyzer Fujifilm BAS-1800II and quantified.

\section{Immunoprecipitation and Western blot analysis}

Total cell lysates were prepared in radioimmune precipitation assay buffer $(1 \times$ PBS, $1 \%$ Nonidet P-40, $0.5 \%$ sodium deoxycholate, $0.1 \%$ sodium dodecyl sulfate (SDS), $10 \mu \mathrm{g} / \mathrm{ml}$ phenylmethylsulfonyl fluoride (PMSF), $60 \mu \mathrm{g} / \mathrm{ml}$ aprotinin, and $1 \mathrm{mM}$ sodium orthovanadate). The lysates were centrifuged at $10000 \mathrm{~g}$ for $10 \mathrm{~min}$ to remove cell debris. Supernatants $(100 \mu \mathrm{g})$ were immunoprecipitated with polyclonal anti-rabbit anti-p19 antibody (Santa Cruz). The immune complexes were recovered on protein $\mathrm{A} / \mathrm{G}$ agarose beads (Santa Cruz) for $1 \mathrm{~h}$ at $4{ }^{\circ} \mathrm{C}$ and then washed four times with PBS. The precipitated proteins were resuspended in sample buffer containing $2 \%$ SDS and $30 \mathrm{~mm} \beta$-mercaptoethanol, boiled for $3 \mathrm{~min}$, fractionated by SDS-PAGE on a $12 \%$ gel, and thereafter blotted to a nitrocellulose membrane. The membrane was then immunoblotted with polyclonal anti-rabbit anti-p19. Western blot analysis for p53 and CDK4 was carried out with $20 \mu \mathrm{g}$ of total cell lysates using polyclonal anti-human p53 and CDK4 polyclonal antibodies (Santa Cruz). $\beta$-Actin antibody (Santa Cruz) was used to ensure equal protein content. The antibodies were detected using horseradish peroxidase-linked goat anti-rabbit IgG (Santa Cruz) and visualized by the Pierce Super Signal Ultra Chemiluminescence signaling system and a Bio-Imaging Analyser Fujifilm LAS-1000. Control for equal gel loading was carried out by Coomasie Blue staining.

\section{Flow cytometry analysis}

Adherent cells were washed and harvested in $1 \mathrm{ml}$ PBS containing $10 \%$ FCS. Cellular pellet was resuspended in $100 \mu \mathrm{l}$ of PBS and fixed by dropwise addition of $1 \mathrm{ml}$ of methanol and rested overnight at $4^{\circ} \mathrm{C}$. The fixed cells were then centrifuged and resuspended in $200 \mu \mathrm{l}$ of RNAse A $(250 \mu \mathrm{g} / \mathrm{ml})$ and incubated for $30 \mathrm{~min}$ at $37^{\circ} \mathrm{C}$. Cells were centrifuged and resuspended in $200 \mu \mathrm{l}$ of $50 \mu \mathrm{g} / \mathrm{ml}$ propidium iodide. Cells were then analysed for DNA content by flow cytometry on a FACScan (Becton Dickinson Immunocytometry Systems, San Jose, CA, USA). Data were analysed using the computer program WinMDI (version 2.8).

\section{Immunofluorescence staining}

Cells were seeded onto glass coverslips and allowed to attach for $24 \mathrm{~h}$ before $8 \mathrm{~mJ} / \mathrm{cm}^{2} \mathrm{UV}$ irradiation. At the indicated times, monolayers were washed twice with PBS and cells were fixed with paraformaldehyde in PBS for $30 \mathrm{~min}$ at room temperature. Following two PBS rinses, cells were permeabilized with $0.1 \%$ Triton X-100 in PBS for $10 \mathrm{~min}$, washed, and incubated for $30 \mathrm{~min}$ with $3 \%$ bovine seroalbumin (BSA), 10\% FCS in PBS. Cells were then rinsed once and incubated with polyclonal anti-rabbit anti-p19 (Santa Cruz) diluted 1:500 in antibody buffer (3\% BSA in PBS) for $2 \mathrm{~h}$ at room temperature. Cells were rinsed twice with PBS and once with wash solution (50 mM Tris- $\mathrm{HCl}, \mathrm{pH} 7.2,100 \mathrm{mM} \mathrm{NaCl}, 0.2 \%$ Tween 20) prior to incubation for $1 \mathrm{~h}$ with the secondary antibody (goat anti-rabbit IgG conjugated to fluorescein isothiocyanate (Santa Cruz) diluted 1:200 in the antibody buffer at room temperature in the dark). After rinsing twice with PBS and twice with wash solution, nuclei were co-stained with Hoescht 33258 solution $(3 \mu \mathrm{g} / \mathrm{ml}$ in PBS) for $10 \mathrm{~min}$ at room temperature in the dark, and finally cells were mounted with Mowiol 4-88 antifading agent (Calbiochem). Slides were visualized using an Olympus Fluoview scanning laser biological inverted microscope IX70; images were acquired with a Zeiss AxioCam digital camera, operated by the Axio Vision 3.1 software.

\section{Caspase-3 activity}

Cells were cultured at $1 \times 10^{6}$ cells/well on six-well plates, exposed to $8 \mathrm{~mJ} / \mathrm{cm}^{2} \mathrm{UV}$ radiation, harvested with lysis buffer (50 mM Tris- $\mathrm{HCl}, \mathrm{pH}$ 7.4, 1 mM EDTA, $10 \mathrm{~mm}$ EGTA, $10 \mu \mathrm{M}$ digitonine, $0.5 \mathrm{mM}$ PMSF, $10 \mu \mathrm{g} / \mathrm{ml}$ bisbenzamide, $10 \mu \mathrm{g} / \mathrm{ml}$ pepstatin, and $10 \mu \mathrm{g} / \mathrm{ml}$ aprotinin) at the indicated times, incubated for $30 \mathrm{~min}$ at $37^{\circ} \mathrm{C}$ and centrifuged at $12000 \mathrm{~g}$ for $20 \mathrm{~min}$. The activity of caspase- 3 in $150 \mu \mathrm{l}$ cell lysates was determined using $100 \mu \mathrm{M}$ of the synthetic caspase-3 substrate Ac-DEVD-pNA (Sigma) in reaction buffer (100 mM HEPES pH 7.5, 0.5 mM EDTA, $5 \mathrm{~mm}$ dithiothreitol and $20 \% \mathrm{v} / \mathrm{v}$ glycerol) in a final volume of $300 \mu \mathrm{l}$ and incubated at $37^{\circ} \mathrm{C}$ during $4 \mathrm{~h}$. Color development was measured at $405 \mathrm{~nm}$. Caspase-3 activity was estimated as $A_{405} / \mu \mathrm{g}$ protein $\mathrm{h}$.

\section{DNA fragmentation assay}

Cells were grown on 6-cm tissue culture dishes. After UV treatment, the cells were harvested, washed with ice-cold PBS, centrifuged at $5000 \mathrm{~g}$ for $2 \mathrm{~min}$ and resuspended in $100 \mu \mathrm{l}$ of lysis buffer (10 mM Tris-HCl, pH 7.6, 20 mM EDTA, pH 8.0, $0.5 \% \mathrm{v} / \mathrm{v}$ Tritón X-100). Samples were immediately centrifuged at $3000 \mathrm{~g}$ for $5 \mathrm{~min}$ and the supernatant was transferred to another Eppendorf tube. In all, $100 \mu \mathrm{l}$ of lysis buffer was added to the pellet. Both tubes were incubated with RNAse A $(5 \mu \mathrm{g} / \mu \mathrm{l}), 1 \% \mathrm{SDS}$ for $2 \mathrm{~h}$ at $56^{\circ} \mathrm{C}$. After overnight incubation with proteinase $\mathrm{K}(4 \mu \mathrm{g} / \mu \mathrm{l})$ at $37^{\circ} \mathrm{C}$, precipitation was carried out with $75 \mu \mathrm{l} 10 \mathrm{M}$ ammonium acetate and $450 \mu \mathrm{l}$ of ethanol. After washing once with $70 \%$ ethanol, samples were loaded onto $1.5 \%$ agarose gel, and the DNA was visualized by ethidium bromide staining.

\section{Unscheduled DNA synthesis}

Cells were seeded at $1 \times 10^{6}$ cells/well in six-well plates and kept undisturbed until $80-90 \%$ confluence. Cells were then washed twice with PBS and regular media was substituted for arginine-free medium containing $1 \%$ FCS. After $24 \mathrm{~h}$, the medium was changed to fresh arginine-free medium containing $1 \%$ serum for additional $36 \mathrm{~h}$. We determined that, under these conditions, DNA semi-conservative synthesis was completely inhibited. Cells were washed with PBS and then irradiated with UV and further cultured in fresh arginine-free medium containing $1 \%$ serum and $10 \mu \mathrm{Ci} / \mathrm{ml}$ $\left[{ }^{3} \mathrm{H}\right]$ thymidine. At the indicated times, cells were washed three times with cold PBS, harvested and pelleted at $3000 \mathrm{~g}$ for $5 \mathrm{~min}$. Cells were lysed with $500 \mu \mathrm{l}$ of $5 \%$ TCA for $30 \mathrm{~min}$ and centrifuged at $10000 \mathrm{~g}$ for $10 \mathrm{~min}$. The pellet was washed twice with cold water and resuspended in $1 \mathrm{M} \mathrm{NaOH}$. The incorporated radioactivity was quantified by scintillation counting. Unscheduled DNA synthesis was estimated as $\mathrm{dpm} / \mu \mathrm{g}$ protein.

\section{Acknowledgements}

This work was supported by research grants from Ministerio de Salud de la Nación (Beca Carrillo-Oñativia) and Agencia Nacional de Promoción Científica y Tecnológica. JC is a Graduate Fellow and CV and EC are researcher members of Consejo Nacional de Investigaciones Científicas y Técnicas (CONICET). 
Al-Mohanna MA, Manogaran PS, Al-Mukhalafi Z, Al-Hussein KA and Aboussekhra A. (2004). Oncogene, 23, 201-212.

Bai F, Pei XH, Godfrey VL and Xiong Y. (2003). Mol. Cell. Biol., 23, 1269-1277.

Barret JM, Cadou M and Hill BT. (2002). Biochem. Pharmacol., 63, 251-258.

Bernstein C, Bernstein H, Payne CM and Garewal H. (2002). Mutat. Res., 511, 145-178.

Chan FK, Zhang J, Cheng L, Shapiro DN and Winoto A. (1995). Mol. Cell. Biol., 15, 2682-2688.

Chaussade L, Eymin B, Brambilla E and Gazzeri S. (2001). Oncogene, 20, 6587-6596.

Cheng M, Olivier P, Diehl JA, Fero M, Roussel MF, Roberts JM and Sherr CJ. (1999). EMBO J., 18, 1571-1583.

Chomczynski P and Sacchi N. (1987). Anal. Biochem., 162, 156-159.

Connor B and Dragunow M. (1998). Brain Res. Brain Res. Rev., 27, 1-39.

Cunningham JJ and Roussel MF. (2001). Cell Growth Differ., 12, 387-396.

Dingwall C and Laskey RA. (1991). Trends Biochem. Sci., 16, 478-481.

Dunkern TR, Fritz G and Kaina B. (2001). Oncogene, 20, 6026-6038.

Dyson N. (1998). Genes. Dev., 12, 2245-2262.

Fan C, Yang J and Engelhardt JF. (2002). J. Cell Sci., 115, 4843-4853.

Friedberg EC. (2001). Nat. Rev. Cancer, 1, 22-33.

Guan KL, Jenkins CW, Li Y, O'Keefe CL, Noh S, Wu X, Zariwala M, Matera AG and Xiong Y. (1996). Mol. Biol. Cell., 7, 57-70.

Hahn WC and Weinberg RA. (2002). Nat. Rev. Cancer, 2, 331-341.

Harper JW and Elledge SJ. (1996). Curr. Opin. Genet. Dev., 6, 56-64.

Hengst L and Reed SI. (1998). Curr. Top. Microbiol. Immunol., 227, 25-41.

Hirai H, Roussel MF, Kato JY, Ashmun RA and Sherr CJ. (1995). Mol. Cell. Biol., 15, 2672-2681.

Hoeijmakers JH. (2001). Nature, 411, 366-374.

Hosoi G, Hara J, Okamura T, Osugi Y, Ishihara S, Fukuzawa M, Okada A, Okada S and Tawa A. (1994). Cancer, 73, 3087-3093.

Igney FH and Krammer PH. (2002). Nat. Rev. Cancer, 2, $277-288$

Johnstone RW, Ruefli AA and Lowe SW. (2002). Cell, 108, 153-164.

Lengauer C, Kinzler KW and Vogelstein B. (1998). Nature, 396, 643-649.

Lim MA, Kikani CK, Wick MJ and Dong LQ. (2003). Proc. Natl. Acad. Sci. USA, 100, 14006-14011.

Lukas J, Parry D, Aagaard L, Mann DJ, Bartkova J, Strauss M, Peters G and Bartek J. (1995). Nature, 375, 503-506.

Lutzen A, Bisgaard HC and Rasmussen LJ. (2004). Exp. Cell Res., 292, 123-134.

Malumbres M and Barbacid M. (2001). Nat. Rev. Cancer, 1, 222-231.

Martin GS. (2003). Cancer Cell., 4, 167-174.

Matsuzaki Y, Miyazawa K, Yokota T, Hitomi T, Yamagishi H and Sakai T. (2002). FEBS Lett., 517, 272-276.

Mattaj IW and Englmeier L. (1998). Annu. Rev. Biochem., 67, 265-306.
Milligan A, Gabrielli BG, Clark JM, Hayward NK and Ellem KA. (1998). Mutat. Res., 422, 43-53.

Minella AC, Swanger J, Bryant E, Welcker M, Hwang H and Clurman BE. (2002). Curr. Biol., 12, 1817-1827.

Miyamoto Y, Saiwaki T, Yamashita J, Yasuda Y, Kotera I, Shibata S, Shigeta M, Hiraoka Y, Haraguchi T and Yoneda Y. (2004). J. Cell. Biol., 165, 617-623.

Murray AW. (2004). Cell, 116, 221-234.

Nakayama K. (1998). Bioessays, 20, 1020-1029.

Nayak BK and Das GM. (2002). Oncogene, 21, 7226-7229.

Newton Bishop JA, Harland M, Bennett DC, Bataille V, Goldstein AM, Tucker MA, Ponder BA, Cuzick J, Selby $\mathrm{P}$ and Bishop DT. (1999). Br. J. Cancer, 80, 295-300.

Norbury CJ and Zhivotovsky B. (2004). Oncogene, 23, 2797-2808.

Ortega S, Malumbres M and Barbacid M. (2002). Biochim. Biophys. Acta., 1602, 73-87.

Park DS, Morris EJ, Padmanabhan J, Shelanski ML, Geller HM and Greene LA. (1998). J. Cell Biol., 143, 457-467.

Rittie L and Fisher GJ. (2002). Ageing Res. Rev., 1, 705-720.

Roussel MF. (1999). Oncogene, 18, 5311-5317.

Ruas M and Peters G. (1998). Biochim. Biophys. Acta., 1378, F115-F177.

Rubbi CP and Milner J. (2003). EMBO J., 22, 975-986.

Sadee W, Yu VC, Richards ML, Preis PN, Schwab MR, Brodsky FM and Biedler JL. (1987). Cancer Res., 47, 5207-5212.

Sancar A, Lindsey-Boltz LA, Unsal-Kaccmaz K and Linn S. (2004). Annu. Rev. Biochem., 73, 39-85.

Sandal T. (2002). Oncologist, 7, 73-81.

Scassa ME, Guberman AS, Ceruti JM and Canepa ET. (2004). J. Biol. Chem., 279, 28082-28092.

Serrano M. (1997). Exp. Cell. Res., 237, 7-13.

Shapiro GI, Edwards CD, Ewen ME and Rollins BJ. (1998). Mol. Cell. Biol., 18, 378-387.

Sharpless NE, Bardeesy N, Lee KH, Carrasco D, Castrillon DH, Aguirre AJ, Wu EA, Horner JW and DePinho RA. (2001). Nature, 413, 86-91.

Sharpless NE, Ramsey MR, Balasubramanian P, Castrillon DH and DePinho RA. (2004). Oncogene, 23, 379-385.

Sherr CJ. (2004). Cell, 116, 235-246.

Sherr CJ and Roberts JM. (1999). Genes Dev., 13, 1501-1512.

Sotillo R, Dubus P, Martin J, de la Cueva E, Ortega S, Malumbres $\mathrm{M}$ and Barbacid M. (2001). EMBO J., 20, 6637-6647.

Sun Y, Yuan J, Liu H, Shi Z, Baker K, Vuori K, Wu J and Feng GS. (2004). Mol. Cell. Biol., 24, 1531-1539.

Thullberg M, Bartek J and Lukas J. (2000). Oncogene, 19, 2870-2876.

Trimarchi JM and Lees JA. (2002). Nat. Rev. Mol. Cell Biol., 3, 11-20.

Varone CL, Giono LE, Ochoa A, Zakin MM and Canepa ET. (1999). Arch. Biochem. Biophys., 372, 261-270.

Wang G, Reed E and Li QQ. (2004). Oncol. Rep., 12, 955-965.

Wilson AJ, Arango D, Mariadason JM, Heerdt BG and Augenlicht LH. (2003). Cancer Res., 63, 5401-5407. 
Wu S, Tan M, Hu Y, Wang JL, Scheuner D and Kaufman RJ. (2004). J. Biol. Chem., 279, 34898-34902.

Yokota T, Matsuzaki Y, Miyazawa 5340-5349.

Yuan J and Yankner BA. (2000). Nature, 407, 802-809.
Zindy F, Cunningham JJ, Sherr CJ, Jogal S, Smeyne RJ and Roussel MF. (1999). Proc. Natl. Acad. Sci. USA, 96, 13462-13467.

Zindy F, Quelle DE, Roussel MF and Sherr CJ. (1997a). Oncogene, 15, 203-211.

Zindy F, Soares H, Herzog KH, Morgan J, Sherr CJ and Roussel MF. (1997b). Cell. Growth Differ., 8, 1139-1150. 